\title{
Automatic control and dispatching of charging currents to a charging station for power-assisted bikes
}

\author{
Willy Magloire Nkounga ${ }^{\mathrm{a}, \mathrm{b}, *}$, Mouhamadou Falilou Ndiaye $^{\mathrm{a}}$, Oumar Cisse ${ }^{\mathrm{a}}$, Françoise Grandvaux ${ }^{\mathrm{b}}$, Laurent \\ Tabourot $^{\mathrm{b}}$, Mamadou Lamine Ndiaye ${ }^{\mathrm{a}}$ \\ ${ }^{a}$ Laboratoire Eau-Energie-Environnement-Procédés Industriels, Ecole Supérieure Polytechnique, Université Cheikh Anta Diop, 5085, Sénégal \\ ${ }^{b}$ Univ. Savoie Mont Blanc, SYMME, F-74000 Annecy, France
}

\begin{abstract}
This work deals with the automatic dispatching of the charging currents in a charging station for power-assisted bikes (ebike). The decision variables such as arduousness index and urgency are determined. The arduousness index is carried out from the GPS ride data. Urgency is calculated using the parking time and ebike batteries state of charge. They are used to determine ebike's charging priorities at the charging station using continue fuzzy logic. Photovoltaic power forecasting is determined over the control horizon using the artificial neural network. On the one hand, the values of the priority, the photovoltaic power forecasting and the storage battery's state of charge are calculated. they allow to control the states of the switches associated with each charging spot and the operating mode of the storage battery (source or load) using discrete fuzzy logic. On the other hand, the interest of the ride's arduousness for a charging station is presented. A comparative study between the charging method integrating the ride arduousness and not is carried out. A case study of the polytech Annecy campus at the University of Savoie Mont Blanc in France is proposed. Results show that: the arduousness index is essential for controlling the charging priority of ebikes at the charging station; Fuzzy logic allows to manage the current dispatching on a charging station; taking into account the ride's arduousness allows to save up to 413.03 (Wh) of profit and $97.90 \%$ energy flexibility on the charging station.
\end{abstract}

Keywords: urgency, arduouness index, priority, charging station, power-assisted bike, fuzzy logic, automatic dispatching .

\section{Introduction}

The development of the power-assisted bikes (ebike) has been experiencing significant growth for several years. This growth has given rise to new challenges for the scientific community. Among these challenges, several authors[1][2] have listed: minimize the cost of recharging batteries, reduce peak load due to charging demand, solve the problem of charging stations shortage, optimally manage the existing charging spots, adapt charging according to charging demand. To face

\footnotetext{
*Corresponding author: PO box 5045 Dakar, 74000 Annecy

Email addresses: willy-magloire.nkounga@univ-smb. fr (Willy Magloire Nkounga),

wellymagloire.nkounga@ucad.edu.sn (Willy Magloire Nkounga), mouhamadouf .ndiaye@ucad.edu.sn (Mouhamadou Falilou Ndiaye), oumar . cisse@univ-thies .sn (Oumar Cisse), francoise.grandvaux@univ-smb.fr (Françoise Grandvaux), laurent. tabourot@univ-smb.fr (Laurent Tabourot), mamadoulamine.ndiaye@ucad.edu.sn (Mamadou Lamine Ndiaye)
}

Preprint submitted to Energy Conversion and Management these challenges, several controlled charging schemes are developed in the literature: Indirect control [3][4], bi-directional control [5][6], multi-level control [7][8] and intelligent control [9][10][11]. In this work, an intelligent controlled charging method is proposed. It has the advantage of relying on human knowledge and experience on the system to create a set of rules which make energy source (solar photovoltaic) and loads (electric vehicles) interact[10][5]. Intelligent management of a charging station gives the operator the ability to remotely monitor, control and limit the use of services in order to optimize the energy demand[10]. This management requires the identification of optimization parameters and their implementation using appropriate techniques or intelligent controllers. The optimization parameters include: limit charge/discharge power, cost forecasting, energy balance, average state of charge, initial energy demand, battery capacity, charging station profit, urgency and user's parking time. The most commonly used optimization techniques are 
fuzzy logic, predictive control, meta heuristic method, particle swarm optimization, binary quantum evaluation, multimodal dynamic programming, algorithmic distribution, quality of service (QoS) optimization and genetic algorithm [10].

Fuzzy logic is used in [12][13] to control an electric vehicle charging station using the load peak, the nonlinear dynamic behavior of the batteries and the electric vehicles consumption profile. The results, compared to the uncontrolled charging, showed a decrease of $11.3 \%$ in the maintenance costs and peak load. In [1], the fuzzy logic is used to assign to each vehicle an appropriate charging spot according to its urgency. The considered parameters are the charging time and the parking time; the results showed that the control of the users' urgency can satisfy the charging demand at $100 \%$. In [14][15], the duration and the charge rate of a charging station are controlled using fuzzy logic with charging speed and the state of charge as optimization parameters. The results showed that fuzzy logic increases the operating efficiency of the charging station. The two-stage control of a charging station is performed in [13] using fuzzy logic and the bee colony optimization. The considered optimization parameter is the battery's charge profile. Results showed that the developed method allows to reduce the peak load compared to the charging without control. Predictive control is used in the work [16][17] for the energy management of an electric vehicle charging station, taking into account the arrival time of each vehicle. Cost minimization and frequency regulation are used as objective functions. The developed control has reduced the fluctuation by $5.02 \%$ and manages the charging order of the electric vehicles. In [18], the authors have developed a multi-agent control using the metaheuristic method for a charging station management. Load regulation is used as objective function and the available energy, power demand, charging station profit are used as optimization parameters. The results showed that the developed control allows to maximize the profit. Particle swarm optimization was used to minimize energy losses in an electric vehicle charging station and the results showed a reduction of $1.89 \%$ [19]. Using the genetic algorithm and the particle swarm optimization, multi-objective optimization was developed by the authors [20] to optimize the sizing of a charging station using power fluctuation, demand and charging cost. The results showed that, the used method allows to obtain an optimal sizing with simultaneous optimization of fluctuation and costs. The optimization of the charging services based on the Quality of Service (QoS) technique is applied to manage energy demand in [21].
The results showed an improvement of $6 \%$ compared to the uncontrolled method. Dynamic programming is used to minimize $47.94 \%$ of the electric vehicles charging costs in [22][1] .

These articles cited above deal with the problem of charging station management for electric vehicles. To date, few research works have addressed the problematic of automatic dispatching of charging currents for ebikes charging station. Existing works have addressed the issues of battery distribution in a charging station [23], ebike rental stations [24], optimal location of ebike charging spots [25]. The parameters taken into account are: the number and duration of the ride, the length of the ride, the power of the photovoltaic panels, the number of ebike users. These existing works do not include the characteristics of the rides in the optimization parameters. In order to take these characteristics into account, the ride arduousness is proposed in this study. It completes the optimization parameters such as urgency, priority and storage batteries' state of charge already developed [1][12]. The knowledge of driving profile is helpful since it help to enhance the energy control strategy. This approach is also known for Hybrid electric Vehicle as indicated in [26].

This first contribution allows to:

- control the charging prority of ebike battery,

- evaluate the necessary energy for charging ebike.

To our knowledge, this is the first time the rides' arduousness is developed and used to determine the charging schedule for ebike's batteries at a charging station

In this paper, we propose an intelligent, automatic and charging control for ebike charging station. This station is shown in Fig 1. The charging control is based on the photovoltaic power forecasting and the optimization parameters such as ride's arduousness, urgency, priority and the storage batteries' state of charge (Soc).

- Continue Fuzzy logic is used to determine the priorities.

- Discrete Fuzzy logic is used to optimize the choice of the charging spots.

According to the authors [27][28], Fuzzy logic allows to conceptualize the fuzziness in a system in a very precise quantifiable parameter, in order to obtain pragmatic solutions. In the energy management integrating photovoltaic solar energy, the 


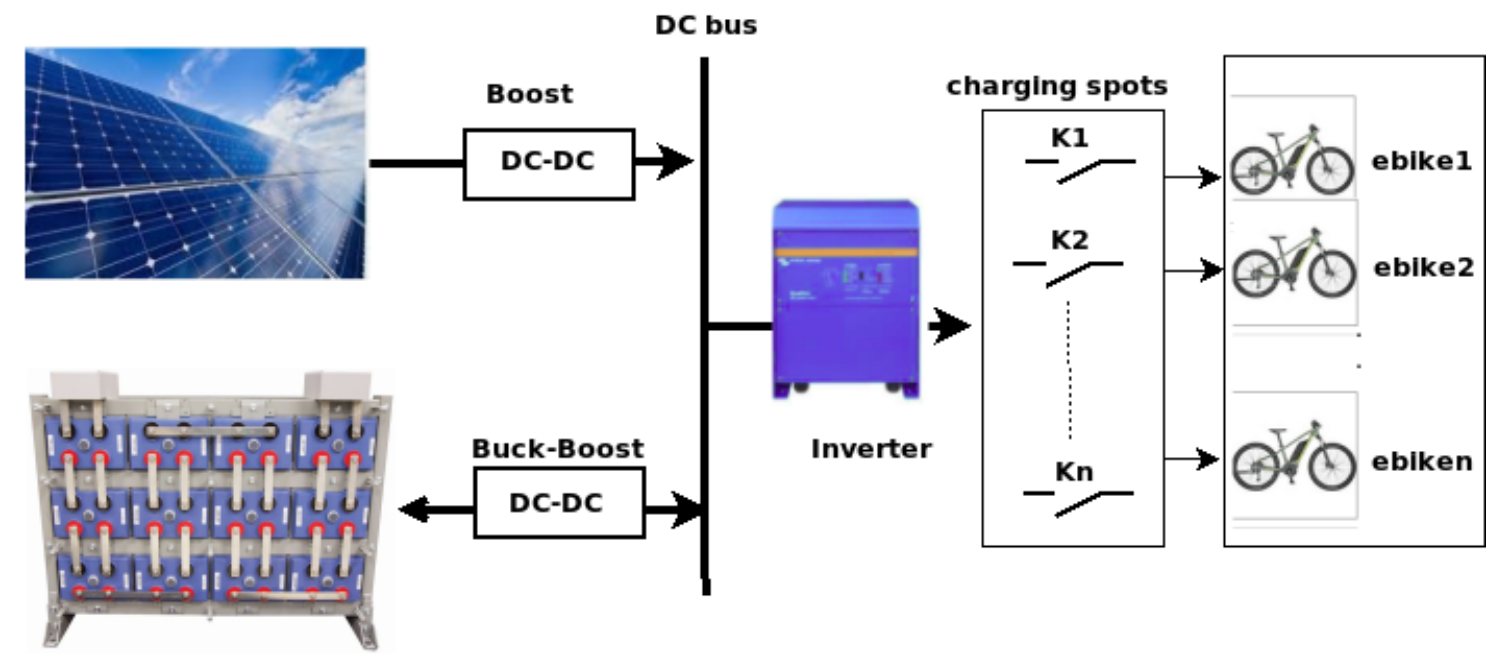

Figure 1: Charging station architecture presentation: It presents the components (sources, converters, switches, power-assisted bikes) and the configuration of the charging station. The ebikes are recharged by using the controllable switches $(\mathrm{k} 1, \mathrm{k} 2, . ., \mathrm{kn})$ on the charging spots.

authors [29] indicate that, for intelligent control with several optimization parameters, fuzzy logic is more adapted because it can take into account several objectives and constraints to find a compromise according to the real situation.

- The estimation of photovoltaic power over a short term horizon is widespread in the literature[30]. Photovoltaic power forecasting over a ten-minute horizon is obtained in the work [31] using artificial neural network (ANN) and the meteorological data; results was obtained with a $99 \%$ correlation. Using ANN, the authors [32] performed solar irradiation forecasting with a correlation coefficient of $86.59 \%$.

In this paper, ANN is used. Its interest has been presented in our previous work [33]. It will allow to quantify the available photovoltaic power over the control horizon. These available photovoltaic power, combined with the state of charge of the storage batteries and the ebike battery charging priority, will allow to control the switches of the charging station using discrete fuzzy logic.

The aims of this work are:

aim1: design and develop an optimization parameter that takes into account the ride's characteristic of the ebike; it is called arduousness index in this work. The variables used are the total distance of the ride, the gradients at the different nodes of the ride, the equivalent of the physical activity and oxygen consumed by the rider on the ride.

aim2: develop a strategy for intelligent control of the ebikes priority on the charging station. It allows to prioritize the charging of one ebike over another in case of simultaneous connection of several ebikes. The continuous fuzzy logic is used. It allows to obtain the priority values between the lower and upper limits established in the fuzzy rules and truth table. The two decision variables used are urgency and arduousness index.

aim3: develop the switches control strategy for the automatic dispatching of charging currents to the various charging spots in the charging station.

Discrete fuzzy logic is used. It allows two possible states for the switches (state 1 or state 0 ). The decision variables are the priority of the ebikes, the photovoltaic power and the storage batteries' state of charge.

aim4: study the interest of the rides' arduousness for the charging stations. The decision variables used are the arduousness gain, the energy consumed by the rider with and without assistance.

The originality of this work lies in several points:

- the design and the implementation of the arduousness index using the ebike ride data (longitude, latitude and altitude), 
- the priority management of an ebike charging station based on the arduousness index,

- the integration of the rides' arduousness in the automatic control of the ebikes charging station,

- the energy management of a charging station using the ride arduousness.

In the remainder of the paper, section 2 presents the architecture of the ebike charging station . Section 3 presents and describes the method used for the management of the charging station. The decision variables, the data acquisition and processing protocol are presented and detailed in this section. Section 4 presents the case study, with results on :

- the urgency criterion,

- physical activity,

- arduousness index,

- the priority,

- the gain in energy called the arduousness gain in this work,

- energy flexibility on the charging station,

- the dispatching of charging currents at the charging station.

Discussions of the results are presented in the section 5. Sections 6 and 7 present the conclusion and perspectives respectively.

\section{Presentation of the ebike charging station}

The charging station configuration is shown in Fig 1. It consists of photovoltaic solar panels (PV), storage batteries, load controller and inverter. The PV produce under solar irradiance, the energy necessary to supply the charging station. The DC/DC controllers make it possible to adapt the output voltage from PV and storage battery to the DC-bus voltage. In the absence of load (ebike), the solar energy from the PV is stored directly in the storage batteries via a bidirectional buckboost controller. These batteries provide energy in case of energy shortage (lack of irradiance, high charging demand) and store in the absence charging demand. The full description of the Fig 1 is provided in our previous work [34]. The DC/AC inverter makes it possible to adapt the DC bus voltage for the ebike battery charger. Controllable switches are used for energy dispatching to the ebikes. The control of the switches is performed using discrete fuzzy logic.

\section{Methods}

The operating synoptic of the charging station is shown in Fig.2.

\subsection{Estimation of the ride's arduousness index}

The arduousness index characterizes the level of positive gradient (difficulty) on the ride from the departure (D) to the arrival $\left(A_{r r}\right)$. It does not depend on the ebike battery's state of charge but exclusively on the ride. Therefore, only GPS data are necessary to calculate the arduounous index.

Let $D \rightarrow A_{r r}$ be the ride's distance, $a_{1}, a_{2}, \ldots \ldots, a_{n}$ the successive nodes on the ride $D \rightarrow A_{r r}$ and $n$ the total nodes on the ride (see Fig. 3).

The calculation of the arduousness index requires several steps:

step 1: calculation of the ride distance. It is distributed between the consecutive nodes of the ride from the departure to the arrival place. The distance is calculated using equation (1) [35];

$$
\begin{aligned}
& \text { distance }\left(\mathrm{a}_{z} \rightarrow a_{z+1}\right)=\mathrm{R} \times \arccos \left\{\sin \left(\text { lata }_{z}\right) \times \sin l a t a_{z+1}+\right. \\
& \left.\cos \text { lata }_{z} \times \cos \text { lata }_{z+1} \times \cos \left(\text { longa } a_{z+1}-\text { Longa }_{z}\right)\right\} \\
& R \quad \text { earth's radius } \\
& a_{z}, a_{z+1} \quad \text { consecutive nodes on } \\
& \text { the ride } a_{z} \rightarrow a_{z+1} \\
& \text { lata }_{z}, \text { lata }_{z+1} \quad \text { the latitudes of } a_{z} \text { and } a_{z+1} \\
& \text { Longa }_{z}, \text { Longa }_{z+1} \quad \text { the longitudes of } a_{z} \text { and } a_{z+1}
\end{aligned}
$$

step 2: calculation of the average slope $S_{z}(\%)$ of the ride. Equation (2) is used. $\Delta h$ designates the difference in altitude between nodes $a_{z}$ and $a_{z+1}$

$$
S_{z}(\%)=\left(\frac{\Delta h\left(a_{z} \rightarrow a_{z+1}\right)}{\text { distance }\left(a_{z} \rightarrow a_{z+1}\right)}\right)
$$

step 3: the traction power provided by the rider. It is calculated using equation (3) [36]

$\mathrm{W}_{m, z}=\frac{C_{v}}{\eta_{\text {mech }}}\left[M \times g \times\left(C_{r}+\frac{S_{z}}{100}\right)+0.5 \times C_{d} \times A \times \rho \times\left(C_{v}+C_{w}\right)^{2}\right]$

$C_{v} \quad$ the rider's speed

$\eta_{\text {mech }} \quad$ the mechanical performance of the ebike

$M \quad$ cumulative mass (rider + ebike)

$g \quad$ acceleration of gravitational forces

$C_{r} \quad$ the rolling resistance coefficient

$S_{z} \quad$ the slope of the ride $a_{z} \rightarrow a_{z+1}$

$C_{d} \quad$ the aerodynamic coefficient

$A \quad$ the front surface of the set (ebike,rider)

$\rho \quad$ the air density

$C_{w} \quad$ the opposite wind speed 


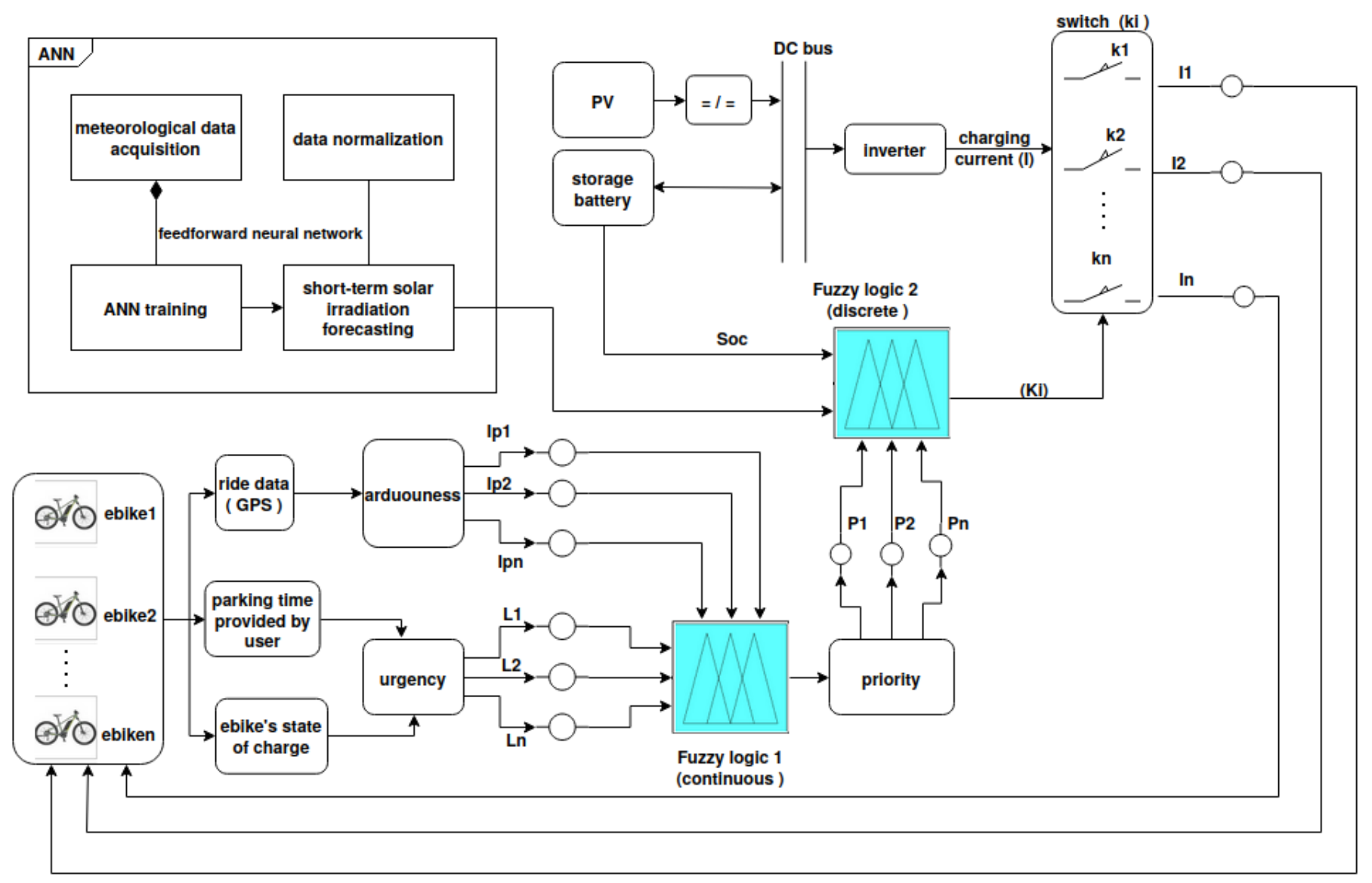

Figure 2: operating synoptic used for the ebike charging station: The switches allow to decide whether to supply the charging current to each connected ebike or not. It depends on the ride's characteristics, parking time, the storage battery state of charge (initial and desired) and the available photovoltaic power. 


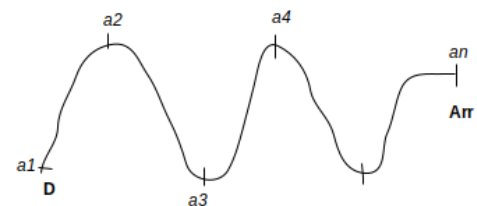

Figure 3: illustration of the nodes on the ride. each ride is divided into several parts delimited by nodes; the distance and altitude between two consecutive nodes are calculated to determine the average slope $S_{z}(\%)$. The values of $S_{z}(\%)$ are used to calculate the cumulative physical activity of the rider throughout the whole ride and the arduousness index. This index is coupled with the urgency parameter to control the battery charging priority of the power-assisted bike.

step 4: calculation of the oxygen equivalent consumed by the rider. It is calculated using equation (4) [36]

$$
V_{O 2, z}=450+9.7067 \times W_{m, z}
$$

step 5: calculating the rider's equivalent physical activity . Physical activity $A P_{z}$ on the ride $a_{z} \rightarrow a_{z+1}$ is calculating using equation (5) [36]. It is obtained by converting the equivalent of oxygen consumed by the rider into his metabolic equivalent of task (MET). For a person at rest, the volume of equivalent oxygen $(\mathrm{O} 2)$ is fixed at $3.5 \mathrm{ml} / \mathrm{kg} / \mathrm{min}$ for a body mass of $70 \mathrm{~kg}$. [37]

$$
A P_{z}=\frac{1}{3.5} \times\left(V_{O 2, z}\right)
$$

The arduousness index $I_{p}$, along the ride $D \rightarrow A_{r r}$ is then calculated using equation (6) .

$$
I_{p}=\frac{1}{100} \times \sum_{z=1}^{n}\left(\frac{A P_{z}-3.5}{A P_{z}}\right)
$$

The arduousness index allows to prioritize the charging of the ebike batteries that have the highest positive gradients on their rides, in case of simultaneous connection of ebikes on the charging station. The interest of the ride's arduousness and the ebike priority are presented in this work.

\subsection{Urgency of charging a power-assisted bike at a charging station}

The charging urgency defines the suitability of ebike's immediate charge; it is calculated as soon as the ebike charger is connected to a charging spot. The urgency helps to determine the charging priority as well as the arduousness index defined in the previous section. The parameters used to define the urgency are: the parking time and charging time. The latter depends on the difference between the desired and the initial ebike's state of charge. The charging time and the charging urgency are respectively calculated using equation (9) and equation (7) [1].

$$
L_{i}=\frac{t_{i}^{p k}-\Delta t_{i}}{\Delta t_{i}}
$$

$t_{i}^{p k}$ is the ebike parking time at the charging station, it is calculated using equation (8)

$$
t_{i}^{p k}=t_{i}^{d p}-t_{i}^{a r}
$$

$t_{i}^{d p}, t_{i}^{a r}$ are respectively the departure and arrival times of the rider at the charging station. $\Delta t_{i}$ is the charging time of the ebike's battery calculated from equation (9).

$$
\Delta t_{i}=\frac{\left(\operatorname{socev}_{m}-\operatorname{socev}_{o}\right) \times E_{i}^{e v}}{\eta \times p_{i}^{e v}}
$$

$$
\begin{array}{ll}
E_{i}^{e v} & \text { charging energy of the ebike's battery } \\
\eta & \text { charging efficiency } \\
p_{i}^{e v} & \text { the average charging power } \\
\text { socev }_{m} & \text { desired state of charge of the ebike's battery } \\
\text { socev }_{o} & \text { the initial state of charge of the ebike's battery }
\end{array}
$$

From a physical point of view, a scalar value $\mathrm{L}$ of the urgency corresponds to $(\mathrm{L}+1)$ times the parking time.

\subsection{Charging priority for power-assisted bike}

The priority is the output variable of the continuous fuzzy logic. It allows to prioritize in case of simultaneous connection, the charging of the ebike that has the highest arduousness index. To obtain the charging priority, rules are established between the input (urgency, arduousness index) and output (priority) variables. The truth values of these variables are then used to generate the corresponding membership functions.

\section{4. battery assistance in the ride's arduousness}

In the power-assisted mode, ebike's battery provides the necessary energy to support the rider's effort while riding. The value of this energy depends on the arduousness level of the corresponding ride. Knowing the ride's arduousness will help to provide the ebike's battery with the energy required for the ride. This energy can be different from the one desired by the user at the charging station. To calculate the battery assistance level on the rides, several steps are used: 
step1: calculation of the power (energy) expended by the rider in the assisted mode. The assisted mode is the one during which the energy of the ebike's battery is used by the rider. Power is calculated using equation (10) [36].

$$
W_{o, z}=\frac{W_{m, z}}{\left(1+a_{s}\right)}
$$

$a_{s}$ is the assistance ratio given by the system of equation (11) [36]

$$
a_{s}=\left\{\begin{array}{ccc}
1.4 & \text { if } & 0 \leqslant C_{v} \prec 10 \\
1.4-0.1\left(C_{v}-10\right) & \text { if } & C_{v} \geq 10
\end{array}\right.
$$

$C_{v} \quad$ the rider's speed

$W_{o}$ the rider's power in the assisted mode

$W$ the rider's power in the unassisted mode previously given by the equation (3)

step 2: Calculation of the energy expended by the rider when not assisted by the ebike battery while riding; it is calculated using equation (12).

$$
E(W h)=\sum_{z=1}^{n} W_{m, z} \times \Delta t_{z}\left(a_{z} \rightarrow a_{z+1}\right)
$$

$\Delta t_{z} \quad$ ride time between two consecutive nodes $a_{z}$ and $a_{z+1}$;

$W_{m, z} \quad$ the average power of the rider on the ride $a_{z} \rightarrow a_{z+1}$;

step 3: the energy expended by the rider when assisted by the ebike's battery. It is a function of the rider's power in the assisted mode. This energy is calculated using equation (13)

$$
E_{a}(W h)=\sum_{z=1}^{n} W o, z \times \Delta t_{z}\left(a_{z} \rightarrow a_{z+1}\right)
$$

The level of the battery assistance (energy required) is then calculated using equation (14)

$$
\Delta E=E-E_{a}
$$

In the ebike charging process, $\Delta E$ represents the energy that should be provided by the charging station, when the arduousness of the ride is taken into account, i.e. the useful energy to ride.

\subsection{Interest of the ride's arduousness for the charging station}

To determine the interest of the ride's arduousness for the charging station, a comparative study between charging energy with arduousness and without arduousness (no-arduousness) is carried out.

\subsection{1. charging ebike batteries without arduousness}

In the no-arduouness charging mode, the energy supplied to the ebike batteries is based solely on their state of charge. In this charging mode, only the full or desired state of charge of the ebike batteries defines the end of charge; this is a disadvantage in managing the available energy when there is a high charging demand for the ebike batteries at the charging station. The no-arduousness charging energy $\left(E_{c c}\right)$ delivered by the charging station is given by equation (15)

$$
E_{c c}=P_{b} \times \Delta t
$$

$P_{b}$ is the power delivered by the charging station (charging power of the ebike battery) and $\Delta t$ is the charging time calculated earlier in equation (9)

\subsubsection{Gain and energy flexibility of the arduousness charging mode}

The energy gain represents the amount of energy saved at the charging station when the arduousness of the ride is taken into account. To calculate this gain, arduousness and no-arduousness charging mode are applied to each ebike. The difference in energy obtained between the two charging modes represents the energy gain (or arduousness gain) and is calculated using equation (16).

$$
G_{E}(W h)=E_{c c}-\Delta E
$$

To further demonstrate the interest of the ride's arduousness, the energy flexibility on the charging station is calculated using the equation (17).

$$
f(\%)=\frac{E_{c c}-\Delta E}{E_{c c}} \times 100
$$

It allows the charging station owner to know (when arduousness is taken into account) the percentage of energy that can be saved after each charging. Energy flexibility offers several advantages such as:

- redistribution the surplus energy to the ebike's batteries in the parking lot,

- save energy in the storage battery

To know the proportion of energy used on the ride, the variable $\eta(\%)$ is used. It is calculated using the equation (18).

$$
\eta(\%)=\frac{\Delta E}{E_{c c}} \times 100
$$




\section{6. photovoltaic power forecasting}

The flowchart used for forecasting photovoltaic power over the control horizon is presented in Fig.4. Detailed studies on photovoltaic power forecasting such

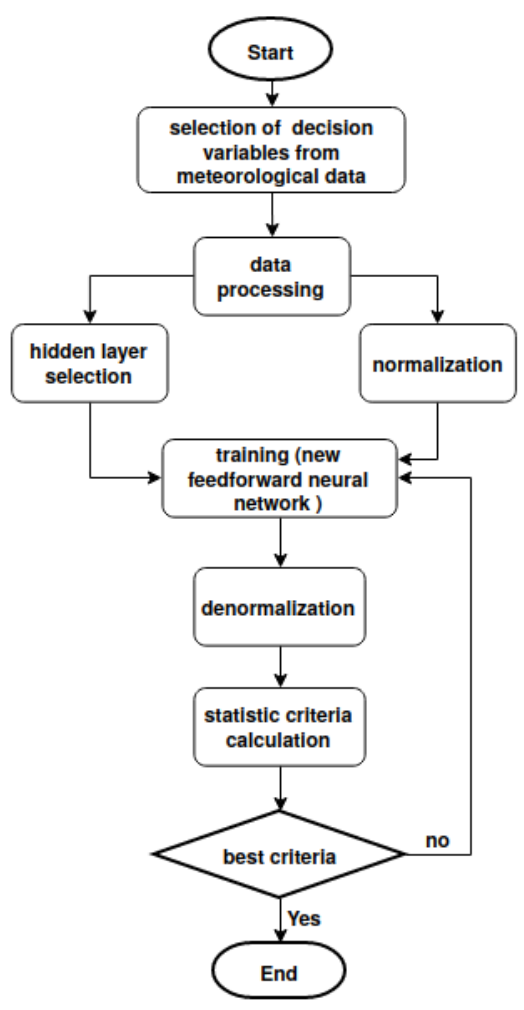

Figure 4: solar irradiation forecasting flowchart. The different steps involved in forecasting photovoltaic power over the control horizon are presented; meteorological data are used.

as the choice of inputs variables with meteorological data, optimal number of hidden layers, normalization and denormalization of variables are conducted in our previous work [33] [38].

\subsection{Decisional flowchart of the charging currents}

The automatic dispatching of the ebike battery charging currents is controlled by the discrete fuzzy logic "fuzzy logic 2" (see Fig.2). The linguistic variables of "fuzzy logic 2" are the storage battery state of charge (Soc), the photovoltaic power, the priority and the state of the switches on the charging spots. The states of the switches $k_{i}$ ( "1" or " 0 ") are set according to the truth values established on the decision variables. In state "0", no current flows through the charging spot. Charging is possible only in state " $1 "$. When the photovoltaic power is low, the storage battery operates in source mode (if it has a considerable state of charge). The flowchart of the charging station control is shown in Fig. 5

\section{Case studies}

\subsection{Context : City of Annecy-le-vieux}

The study context is located in the city of Annecyle-vieux in France. Five rides as shown in Fig.6 are chosen. The global positioning system (GPS) data (longitude, latitude et altitude) of the rides are obtained from the Bikemap [39]. The total distance of each ride are calculated using equation (1). To calculate the total length of each ride, the nodes $a_{1}$ and $a_{n}$ are chosen as the corresponding start and end points. Five rides are used in this study. They are shown in Table 1. This data

\begin{tabular}{|l|l|l|l|}
\multicolumn{4}{c}{} \\
\cline { 2 - 4 } \multicolumn{1}{c|}{} & distance $(\mathrm{km})$ & departure (workplace) & arrival (home) \\
\hline ride 1 & 6.76 & Polytech Annecy & Cran-Gevrier \\
\hline ride 2 & 2.5 & polytech Annecy & "collège évire" \\
\hline ride 3 & 4.7 & polytech Annecy & "gare routière" \\
\hline ride 4 & 7.35 & polytech Annecy & Meythet \\
\hline ride 5 & 5.09 & polytech Annecy & Villaz \\
\hline
\end{tabular}

is used to calculate the values of the charging station's input variables (urgency, arduouness index).

The simulation parameters used in this work are presented in the table 2 and table 3

Table 2: simulation parameters

\begin{tabular}{|c|c|c|}
\hline items & values & units \\
\hline $\mathrm{M}$ & $75(15+60)$ & $\mathrm{kg}$ \\
\hline$\eta_{\text {mech }}$ & 100 & - \\
\hline $\mathrm{g}$ & 9.8 & $\mathrm{~N} / \mathrm{kg}$ \\
\hline$C_{r}$ & 0.008 & - \\
\hline$C_{d}$ & 1.2 & - \\
\hline A & 0.616 & $m^{2}$ \\
\hline$\rho$ & 1.226 & $\mathrm{~kg} / \mathrm{m}^{3}$ \\
\hline $\mathrm{Cw}$ & 0 & $\mathrm{~m} / \mathrm{s}$ \\
\hline$\Delta x_{\text {minimale }}$ & 15 & minute \\
\hline $\mathrm{Pc}(\mathrm{PV})$ & 230 & Watt-peak \\
\hline $\mathrm{C}$ (storage battery) & 100 & $\mathrm{Ah}$ \\
\hline C(ebike battery) & 13.4 & Ah \\
\hline I(charging current) & 6 & $\mathrm{~A}$ \\
\hline E(ebike battery) & 500 & Wh \\
\hline$t_{\max }^{p k}$ & 10 & $\mathrm{~h}$ \\
\hline initial Soc (storage battery) & 50 & $\%$ \\
\hline control horizon & 1 & minute \\
\hline
\end{tabular}




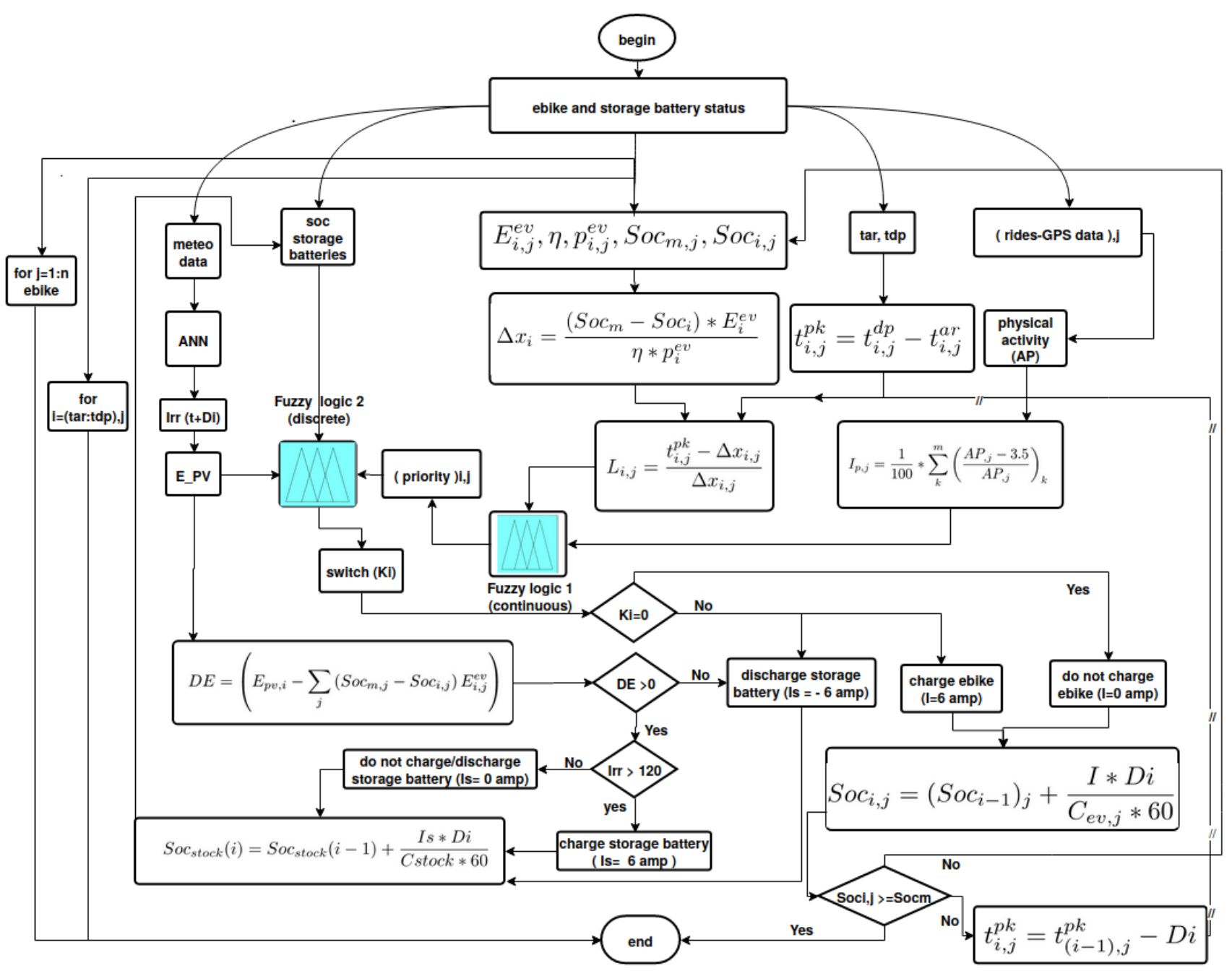

Figure 5: flowchart used to control the charging station. The continuous fuzzy logic (LF1) and the discrete fuzzy logic (LF2) are two different control and command processes. LF1 controls the charging priority of power-assisted bikes at the charging station. LF2 commands the states of the switches taking into account the priority. A Matlab executable program is written respecting the different steps and orientations indicated on the flowchart. The execution of the control program is automated as soon as an electric bike is connected to the charging spot, in order to activate or not the switches that allow to recharge the ebike battery. 


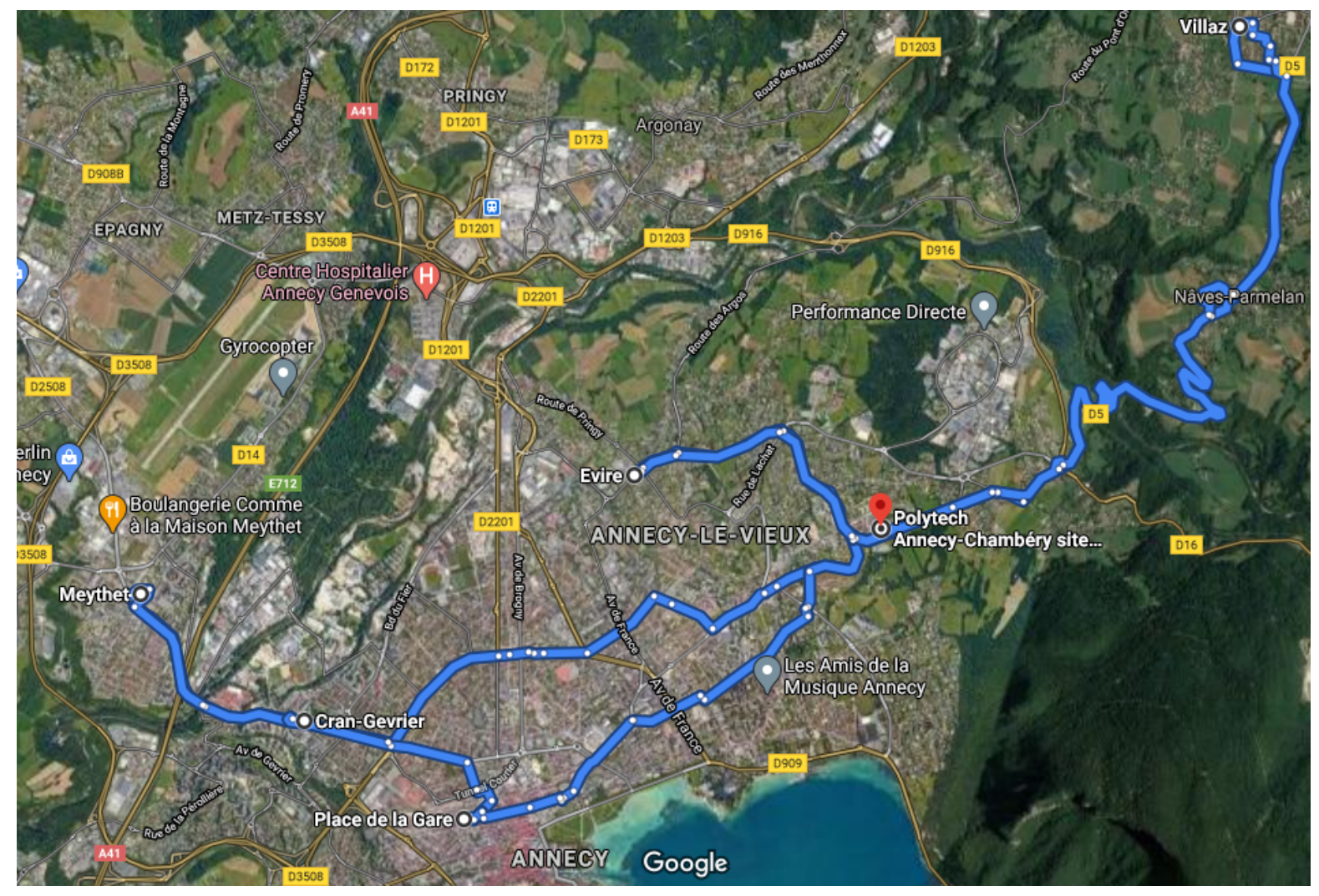

Figure 6: bike's rides. It presents the rides of the power-assisted bikes chosen for the case study in the city of Annecy-le-vieux. The charging station is located at Polytech Annecy. The GPS data of the rides presented are used to evaluate the arduousness of the rides and the physical activity of the rider. 
Table 3: rider's velocity $\left(C_{v}\right)$ [36]

\begin{tabular}{|c|c|c|}
\cline { 2 - 3 } \multicolumn{1}{c|}{} & $\mathrm{S}(\%)$ & $C_{v}(\mathrm{~km} / \mathrm{h})$ \\
\hline uphill & $\geq 2 \%$ & 14.0 \\
& $<2 \%$ & 14.3 \\
\hline downhill & $\geq 2 \%$ & 16.5 \\
\hline straight & $0 \%$ & 15 \\
\hline
\end{tabular}

\section{2. rides profile from the workplace to home}

The altitudes profile on each ride are shown in Fig.7. It shows altitudes on the rides between the workplace and the home of the ebike users. The uphill profiles observed on the rides correspond to the time when the rider must perform a significant amount of physical activity. On the ride 3 , the profile is completely downhill. Ride 5 has the most positive heights differences on its nodes.

\subsection{Physical activities on the rides}

The cumulative physical activity on each ride is shown in Fig.8. It is calculated using equation (19)

$$
A P=\sum_{z=1}^{n} A P_{z}
$$

The results show that, the physical activity changes on the different rides. This change does not depend on the length of the rides, but rather on the altitudes between the different nodes. In other words, it depends on the slope's stiffness on the different rides. Indeed, on the longest ride (ride 4: $7.35 \mathrm{~km}$ ), the cumulative physical activity is $1399.40 \mathrm{MET}$, unlike $1552.80 \mathrm{MET}$ on the ride 1 (Polytech-Annecy, Cran-Gevrier $(6.76 \mathrm{~km})$ ) and 1907.80 MET on the ride 5 (Polytech-Annecy, Villaz). Similarly, the differences between the cumulative physical activities observed on the ride $2(2.5 \mathrm{~km})$ and ride $3(4.7 \mathrm{~km})$ are small compared to their respective distances. The greater the cumulative physical activity, the more arduous the ride. The value of physical activity on each ride is presented in the Table 4

Table 4: values of physical activity between the workplace and home \begin{tabular}{|l|l|l|}
\hline rides: departure (workplace), arrival (home) & distance (km) & Physical activity (Met) \\
\hline
\end{tabular}

\begin{tabular}{|l|l|l|}
\hline ride 1: Polytech Annecy, Cran-Gevrier & 6.76 & 1552.80 \\
\hline ride 2: polytech Annecy, collège évire & 2.50 & 606.45 \\
\hline ride 3: polytech Annecy, gare routière & 4.70 & 740.38 \\
\hline ride 4: polytech Annecy, Meythet & 7.35 & 1399.40 \\
\hline ride 5: polytech Annecy, Villaz & 5.09 & 1907.80
\end{tabular}

\section{4. battery assistance}

Figure 9 shows the amount of energy with and without assistance, expended by the rider on the different rides. The subtraction between the energy expended by the rider in the assisted and no-assisted mode represents the assistance level or the energy required $\Delta E$, that the battery must provide to assist the rider on the ride. Figure 9 shows that, energy depends on the ride's characteristics. The harder the ride, the higher the energy assistance from the ebike battery. The values of the consumed energy with and without assistance, as well as the energy reguired, are shown in the Table 5

Table 5: battery assistance

\begin{tabular}{|c|c|c|c|}
\hline rides & \multicolumn{2}{|c|}{ energy (Wh) } & $\Delta \mathrm{E}(\mathrm{Wh})$ \\
\hline & $\mathrm{E}$ (without assistance) & $\mathrm{Ea}$ (with assistance) & $\mathrm{E}-\mathrm{Ea}$ \\
\hline ride 1 & 40.40 & 16.83 & 23.56 \\
\hline ride 2 & 11.11 & 4.63 & 6.48 \\
\hline ride 3 & 15.19 & 6.33 & 8.86 \\
\hline ride 4 & 31.6 & 13.17 & 18.40 \\
\hline ride 5 & 85.58 & 35.65 & 49.92 \\
\hline
\end{tabular}

\subsection{Arduousness index}

The arduousness index of each ride is presented in Fig.10. The ride with the highest arduousness index is the most arduous for the rider. It corresponds to the ride 5 (0.99), followed respectively by the ride $1(0.60)$, ride $4(0.45)$, ride $2(0.21)$ and ride $3(0.20)$. The arduousness index of the rides varies in the same way as the slope on the nodes: the higher the slopes, the higher the arduousness index. In other words, the stiffer the ride, the higher the arduousness index. The value of the arduousness index on each ride is shown in the Table 6

Table 6: values of the arduouness index between the workplace and home

\begin{tabular}{|l|l|l|}
\hline rides: departure (workplace) - arrivall home) & distance $(\mathrm{km})$ & Ip (without unit) \\
\hline ride 1: Polytech Annecy, Cran-Gevrier & 6.76 & 0.60 \\
\hline ride 2: polytech Annecy, collège évire & 2.5 & 0.21 \\
\hline ride 3: polytech Annecy, gare routière & 4.7 & 0.20 \\
\hline ride 4: polytech Annecy, Meythet & 7.35 & 0.45 \\
\hline ride 5: polytech Annecy, Villaz & 5.09 & 0.99 \\
\hline
\end{tabular}

\section{6. priority rules for ebike charging}

The ebike priority is obtained from the continuous fuzzy logic "fuzzy logic 1". The truth table of input and output variables are presented in the table 7 . The membership functions and their truth values are presented in Fig. 11 .

The zero value of the arduousness, observed on the membership function ( Fig.11)corresponds to the physical activity at rest and the rides with a slope less than 

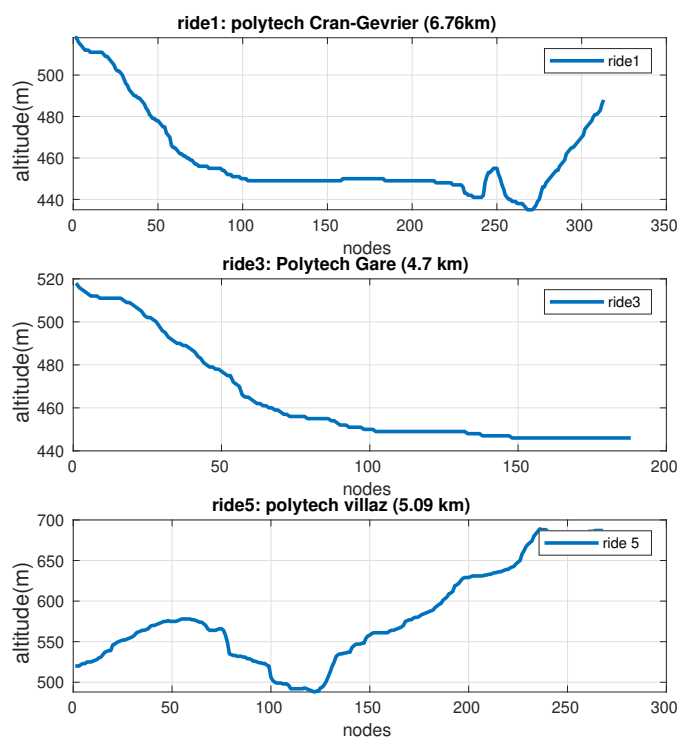
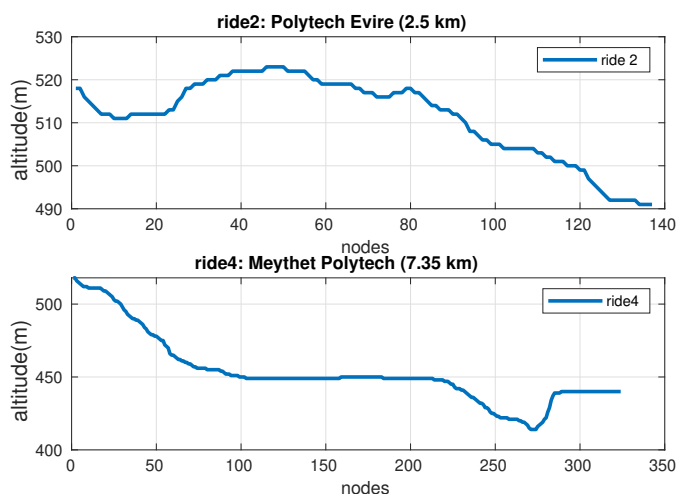

Figure 7: difference in height on the rides versus the nodes. It shows the profile of the altitudes on the different nodes of the rides. Slopes below zero correspond to the downhill and positive slopes to the uphill. These profiles are used to calculate the arduousness of the rides and the physical activity of the rider.

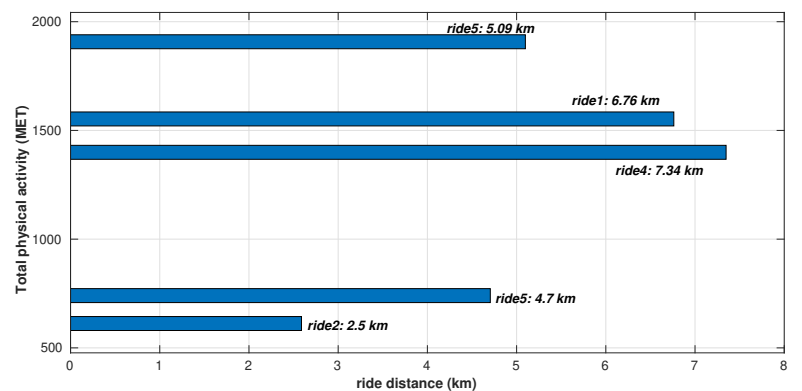

Figure 8: Cumulative physical activity on the rides. It is the total physical effort that a rider must make to complete each ride while riding. The unit (MET) represents the metabolism of equivalent tasks.

Table 7: truth table of priority

\begin{tabular}{|c|c|c|}
\hline Urgency & arduouness & Priority \\
\hline extreme,high,medium,low & high & high \\
\hline extreme,high & medium & high \\
\hline medium,low & medium & medium \\
\hline extreme, high, medium, low & low & low \\
\hline
\end{tabular}

or equal to zero. When a slope is below zero, the corresponding physical activity for the rider is considered at rest (3.5 MET); this approach is also considered in

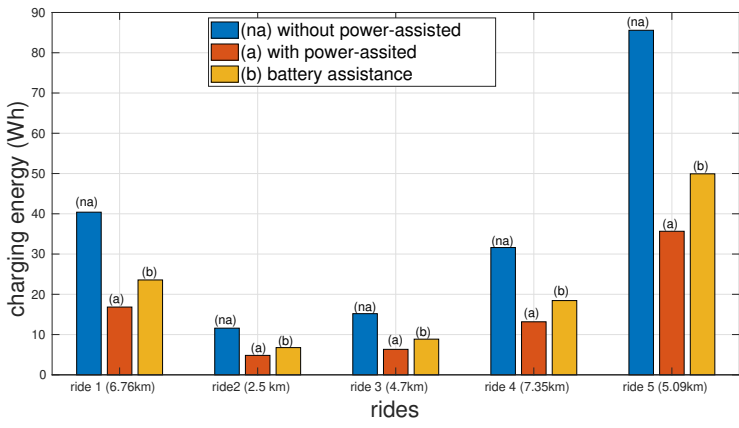

Figure 9: rider's energy on the both assistance and no assistance mode: "without power-assisted" refers to the energy expended by the rider while riding; this energy is expended when the rider is not assisted. "with power-assisted" represents the amount of energy expended by the rider when assisted by the ebike battery. The "battery assist" is the energy provided by the battery to assist the rider on the ride. It is obtained from the subtraction between the energy expended by the rider in the two modes (assisted and unassisted).

[36]. The low value of the arduousness corresponds to the slope values below $1.5 \%$. During this stage, the rider has two possibilities:

- do not perform any physical activity when the slope is less than zero, as it corresponds to a downhill; 


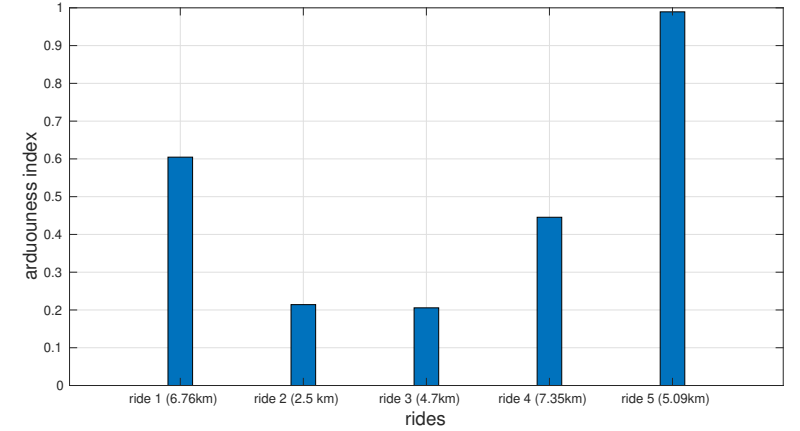

Figure 10: arduouness index. This is the optimization parameter used to prioritize power-assisted bikes at the charging station. The closer the arduousness index is to 1, the more arduous the ride for the rider.

- perform a low physical activity of $4.9 M E T$ if it is on a horizontal ride.

The medium arduousness corresponds to the slopes from $] 1.5 \%-4 \%$ ] and the physical activities from 14.9-8.3](MET). In this case, the rider needs a significant effort to pul his ebike. High arduousness, corresponds to acute slopes (more than 4\%). Here, the rider would not be able to perform the riding over a long distance without assistance.

Concerning the membership function of urgency, the description is mentioned in the Table 8. The maximum parking time and minimum charging time values are shown previously in the Table 2

Table 8: explaination of the urgency membership function

\begin{tabular}{|c|c|}
\hline urgency & meaning \\
\hline E(extreme $)$ & $t^{p k} \prec \Delta x$ \\
\hline high & $\Delta x<t^{p k} \leq 2 \Delta x$ \\
\hline medium & $2 \Delta x<t^{p k} \leq 4 \Delta x$ \\
\hline low & $4 \Delta x<t^{p k} \leq 40 \Delta x$ \\
\hline
\end{tabular}

\subsection{Priority area for power-assisted bikes on the charging station}

The output value of the priority versus the input variables (urgency and arduousness) is shown in Fig.12. It presents the overall values, necessary for the global management of user priority on the charging station, taking into account the truth values of the input. In other words, it is the set of the possible values the priority can have. Figure 12 constitute the possible values of the input and the output variables. Their corresponding memberships functions are shown in Fig.11
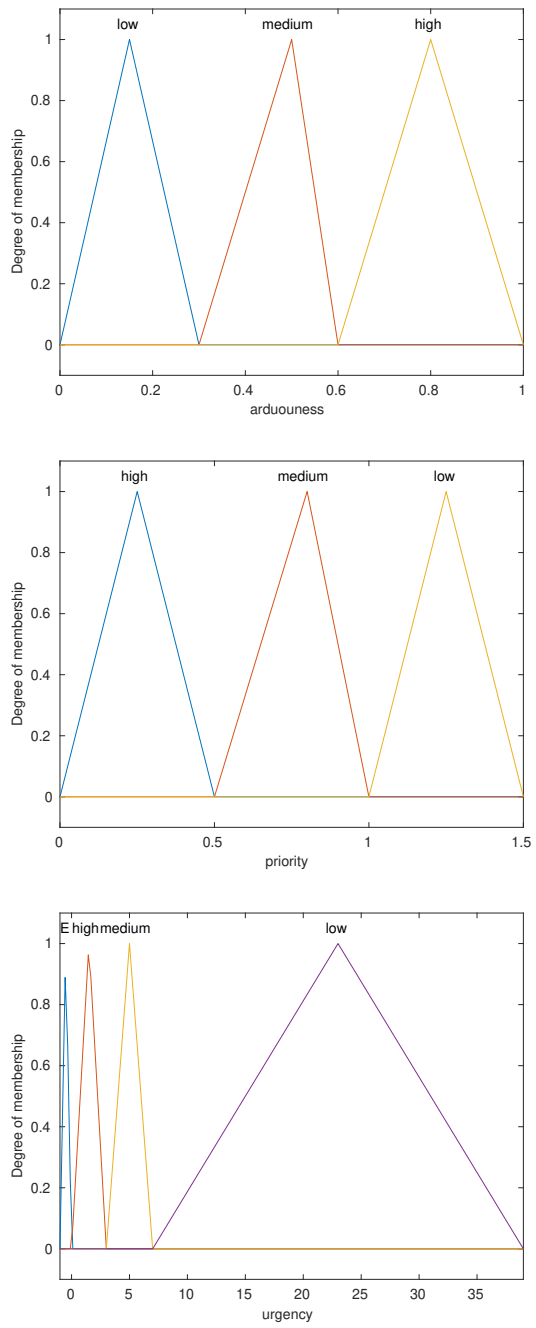

Figure 11: membership functions used for priority control. It is the subdivision of the used variables into several levels. These variables are: priority, arduousness and the storage battery state of charge. The priority control of the power-assisted bikes is carried out using the arduousness and state of charge of the storage battery.

\subsection{Automatic switch control}

The dispatching of the charging currents to the switches is controlled by "fuzzy logic 2". It sets the switches in two states:

- state 1: The switch is closed; a charging current flows through the charging spot. $(I \neq 0)$

- state 0: the switch is open; no current is flowing through the charging spot. $(I=0)$

The truth values used to control the switches are shown in Table 9. The fuzzy logic 2 membership functions and 

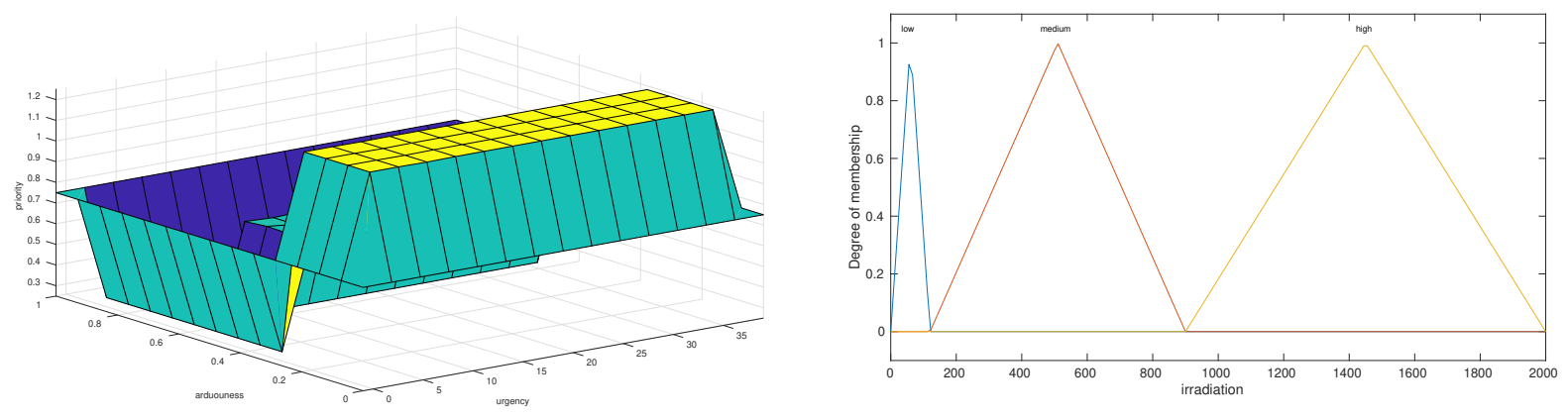

Figure 12: priority surface. Three levels of priorities (high, medium, low) are obtained with fuzzy logic. They are obtained using the rules established on the priority and urgency values.

Table 9: truth table used to control the switches

\begin{tabular}{|c|c|c|c|}
\hline solar irradiation $\left(\mathrm{W} / \mathrm{m}^{2}\right)$ & SOC $(\%)$ & priority & switch \\
\hline low & low & High, medium, low & 0 \\
\hline low & medium, high & high, medium, low & 1 \\
\hline medium & low & high, medium & 1 \\
\hline medium & low & low & 0 \\
\hline medium & high,medium & high,medium,low & 1 \\
\hline high & - & - & 1 \\
\hline \multicolumn{4}{|c}{}
\end{tabular}

their truths values are shown in Fig.13. The membership function of the input variable "priority" is already presented above in Fig.11, i.e. the output obtained with the intelligent control "fuzzy logic 1". Solar irradiation is considered low for values between $[0-120]\left(\mathrm{W} / \mathrm{m}^{2}\right)$; this choice is justified by the fact that, the solar irradiation threshold for solar panel production is around $120 \mathrm{~W} / \mathrm{m}^{2}$. For values between $[900-2000]\left(\mathrm{W} / \mathrm{m}^{2}\right)$, solar irradiation is considered high. Indeed, most of the electrical characteristics provided on the photovoltaic solar panel are obtained under standard test condition $\left(1000 \mathrm{~W} / \mathrm{m}^{2}\right)$. Moreover, the maximum irradiation at the study site is close to $1890 \mathrm{~W} / \mathrm{m}^{2}$ in summer.

\subsection{Selection of the charging currents}

The dispatching of the charging currents to the ebike is controlled by the aggregation surface obtained with the truths values of the "fuzzy logic 2". This surface is shown in Fig14. It constitutes the set of values on the switches' states versus the solar irradiation and the storage battery state of charge.

\subsection{0. photovoltaic power forecasting from the artificial neural network}

In this work, meteorological data are used to forecast the available power of the photovoltaic panels over the control horizon (1 $\mathrm{min}$ ). The meteorological data used are those of the year 2015, from January 01, 2015 to

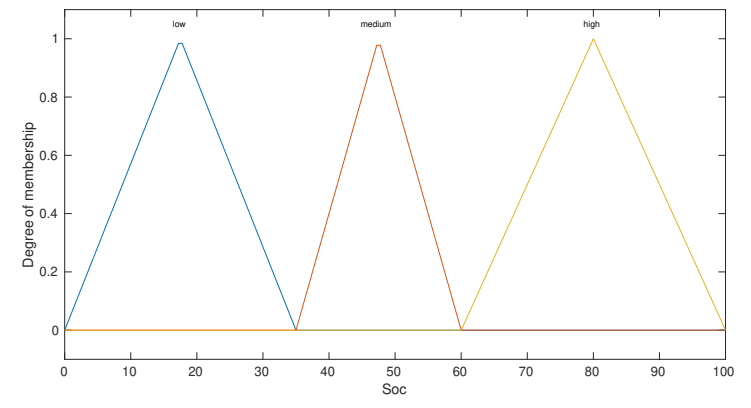

Figure 13: membership function of the switches control variables: solar irradiation is used to determine the availability of photovoltaic power over the control horizon. This power and the state of charge of the storage battery are used to control the state of the switches using discrete fuzzy logic.

December 31, 2015 on the Annecy-le-vieux site. These data are obtained from the Soda database [40]. The simulation parameters used for the ANN training are presented in table $10.70 \%$ of the data are used for training and $30 \%$ for validation. The training performances on

Table 10: ANN parameters

\begin{tabular}{|c|c|c|c|}
\hline training & validation & number of hidden layer & number of iteration \\
\hline $70 \%$ & $30 \%$ & 03 & 1000 \\
\hline
\end{tabular}

the ANN are shown in Fig.15. The forecasting is obtained with a correlation of $99 \%$ after six hundred and forty-nine (649) iterations. Fig.16 presents the comparison between the measured and forecasted solar irradiation at the Annecy-le-vieux site. The results obtained show a perfect concordance between the measured values and the forecasted values on the site, which makes it possible to validate the process used as well as the results obtained with the forecasting on the site.

\subsection{Application of the developed command and con- trol to a ebike charging station}

To check the applicability of the developed control, two charging scenarios are defined. 


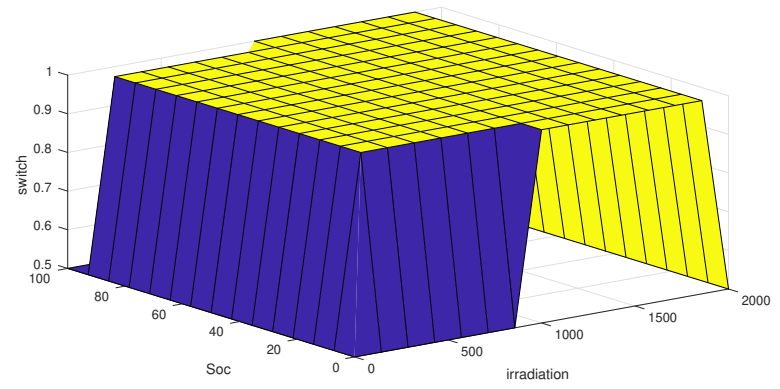

Figure 14: decision surface for the switches' control. the control provides two possible states ( 0 or 1 ) for the switches, taking into account the solar irradiation values (photovoltaic power) and the battery storage state of charge (soc). In state 1 , current flows through the charging spot unlike the state 0 where there is no current.

\subsection{1. presentation of the charging scenarios}

The ebike data for scenario 1 and scenario 2 are presented in Table 11 and Table 12. We consider the ebike to be connected as soon as they arrive at the charging station.

\begin{tabular}{l} 
Table 11: ebike data for scenario 1 \\
\cline { 2 - 7 } \begin{tabular}{|c|c|c|c|c|c|}
\hline & ebike 1 & ebike 2 & ebike 3 & ebike 4 & ebike 5 \\
\hline arrival time & $10 \mathrm{am}$ & $8 \mathrm{am}$ & $10 \mathrm{am}$ & $9 \mathrm{am}$ & $11 \mathrm{am}$ \\
\hline departure time & $12 \mathrm{am}$ & $2 \mathrm{pm}$ & $10.58 \mathrm{am}$ & $10 \mathrm{am}$ & $5 \mathrm{pm}$ \\
\hline parking time (h) & 02 & 06 & 0.58 & 01 & 06 \\
\hline initial state of charge: Soc $_{o}$ & 30 & 50 & 20 & 38 & 45 \\
\hline desired state of charge: Soc $_{m}$ & 100 & 100 & 100 & 100 & 100 \\
\hline rides & ride 1 & ride 2 & ride 3 & ride 4 & ride 5 \\
\hline
\end{tabular}
\end{tabular}

Table 12: ebike data for scenario 2

Table 12: ebike data for scenario 2
\begin{tabular}{|c|c|c|c|c|c|}
\hline & ebike 1 & ebike 2 & ebike 3 & ebike 4 & ebike 5 \\
\hline arrival time & $10 \mathrm{am}$ & $12 \mathrm{am}$ & $2 \mathrm{pm}$ & $9 \mathrm{am}$ & $1 \mathrm{pm}$ \\
\hline departure time & $12 \mathrm{am}$ & $1 \mathrm{pm}$ & $2.30 \mathrm{pm}$ & $11.30 \mathrm{am}$ & $17 \mathrm{pm}$ \\
\hline parking time (h) & 02 & 01 & 0.5 & 02.5 & 04 \\
\hline initial state of charge:Soc $o$ & 45 & 45 & 45 & 45 & 45 \\
\hline desired state of charge:Socm & 100 & 100 & 100 & 100 & 100 \\
\hline rides & ride 3 & ride 3 & ride 3 & ride 3 & ride 3 \\
\hline
\end{tabular}

In the scenario 1, the parking time, the initial state of charge and rides are different. Only the values of the desired states of charge are similar.

As for scenario 2 (tableau 12), the rides, initial and desired state of charge are similar. The parking times are different.

\subsection{2. switch states on the different scenarios}

Fig. 17 and Fig. 18 present the switch states in the scenarios 1 and 2. Results show that:

- during the scenarios 1 and 2, all the switches are in the state " 1 " at the beginning of the charge;
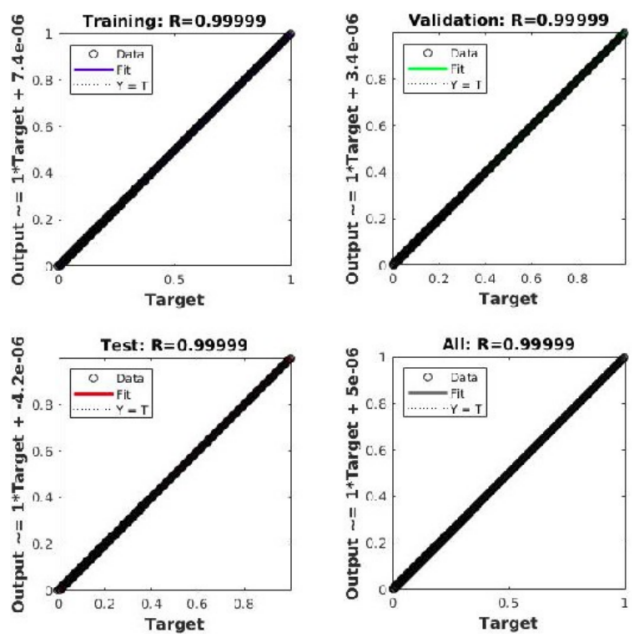

Figure 15: artificial neural network (ANN) training performance: the performance of the ANN is evaluated by the correlation coefficient $\mathrm{R}$. The different training steps applied for forecasting photovoltaic power are presented with their respective performances

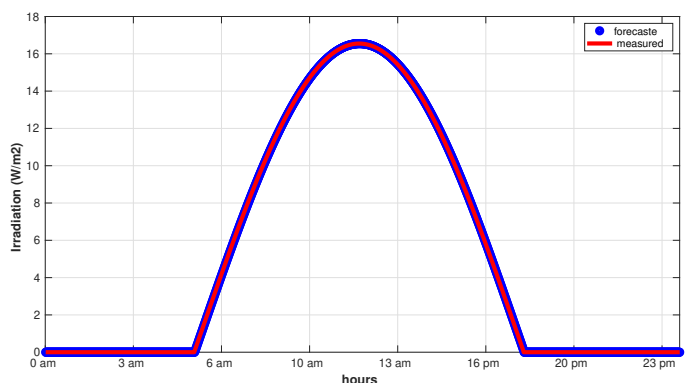

Figure 16: Solar irradiation forecasted: day of September 14, 2015. This curve compares the solar irradiation values measured at the site and the values from the forecasting with the artificial neural network.

- the switches of ebike 1 , ebike 2 , ebike 3 , ebike5 in the scenario 1 and ebike 1 , ebike 4 , ebike 5 in the scenario 2 are shifted from "state 1 " to "state 0 ";

- the ebike 4 in the scenario 1 and the ebike 2 , ebike 3 in the scenario 2 are in state " 0 " during the whole parking time.

The changes observed on the switch states are discussed in this work.

\subsection{3. riders' priorities on the different scenarios}

The priorities of ebike on the scenarios 1 and 2 are presented in Fig.19 and Fig.20 respectively. Results show that: 


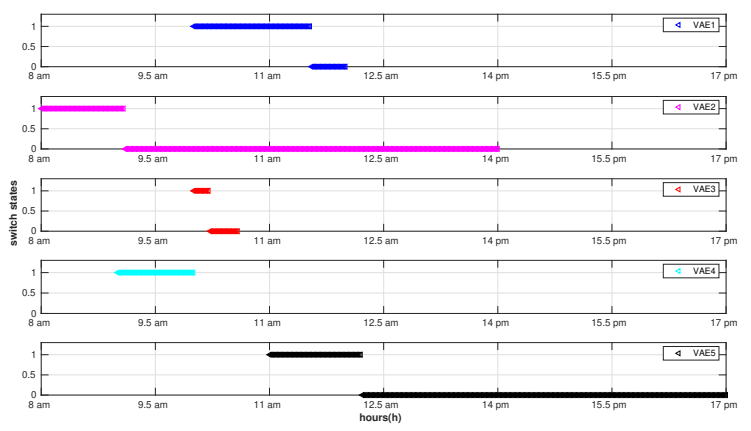

Figure 17: switch states in scenario 1. In state "1", ebike's battery is charging; the switch allows a current to flow through the charging spot. In state " 0 ", no current is flowing through the charging spot.

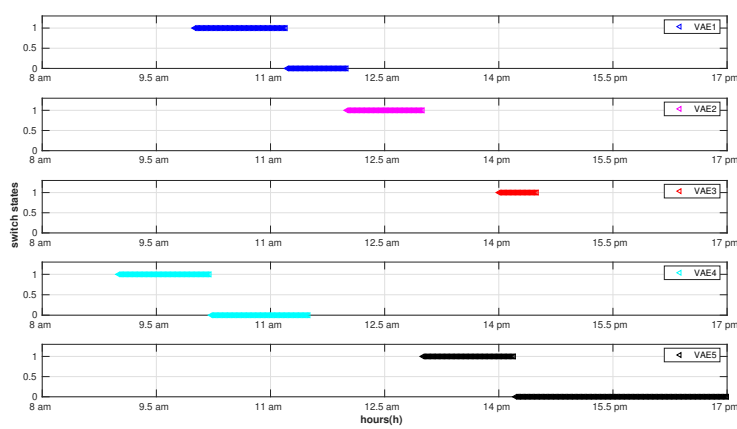

Figure 18: switch states in scenario 2. In state "1", ebike's battery is charging; the switch allows a current to flow through the charging spot. In state " 0 ", no current is flowing through the charging spot.

- ebikes have low priorities during the parking time in the scenario 2 .

- the priority of ebike 4 in the scenario 1 varies from high to medium.

- the ebike 1 and ebike 5 in the scenario 1 have high priority throughout the parking time.

- the ebike 2 (despite its low state of charge 20\%) has a low priority during the entire parking time in scenario 1 .

- the priority of ebike 3 varies from low to high in Scenario 1

The results ont the priorities are discussed in this work.

\subsubsection{Charging urgency on scenarios 1 and 2}

Fig.21 and Fig.22 present the urgencies of ebikes in the scenarios 1 and 2. Results show that:

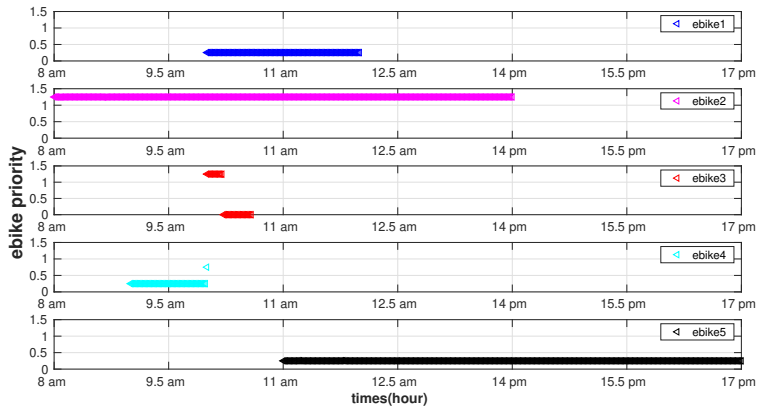

Figure 19: charging priority of scenario 1: below 0.5 , the ebike has a high priority; between 0.5 and 1 , the priority is medium; between 1 and 1.5 , the priority is low. In case of simultaneous connection of the ebikes, the highest priority is privileged on the charging station.

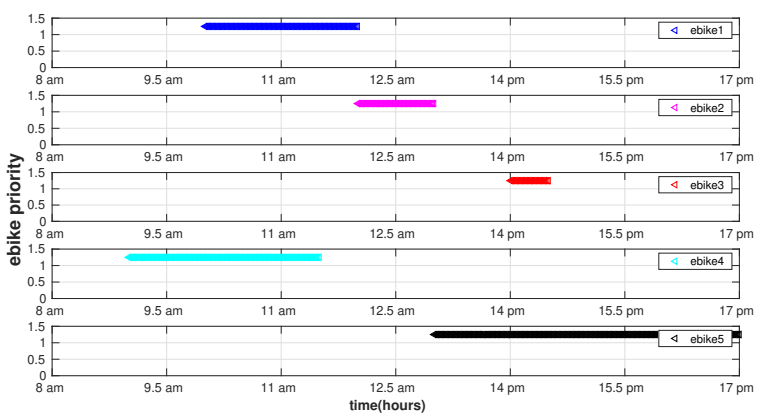

Figure 20: charging priority of scenario 2: below 0.5 , the ebike has a high priority; between 0.5 and 1 , the priority is medium; between 1 and 1.5 , the priority is low. In case of simultaneous connection of the ebikes, the highest priority is privileged on the charging station.

- the urgencies of ebike 3 , ebike 4 in the scenario 1 and ebike 2, ebike 3 in the scenario 2 are extreme throughout the parking time;

- the urgencies of ebike 1 , ebike 2 and ebike 5 in the scenario 1 , then ebike 1 , ebike 4 and ebike 5 in the scenario 2 varie from high to medium and then from medium to low.

The variation observed in the urgency of scenarios 1 and 2 is also discussed in this work.

\section{Storage battery and ebike states of charge}

The storage battery and the ebike state of charge in the both scenario 1 and scenario 2 are shown in Fig 23 and Fig 24 respectively.

\subsection{1. scenario 1}

The results of the scenario 1 show that: 


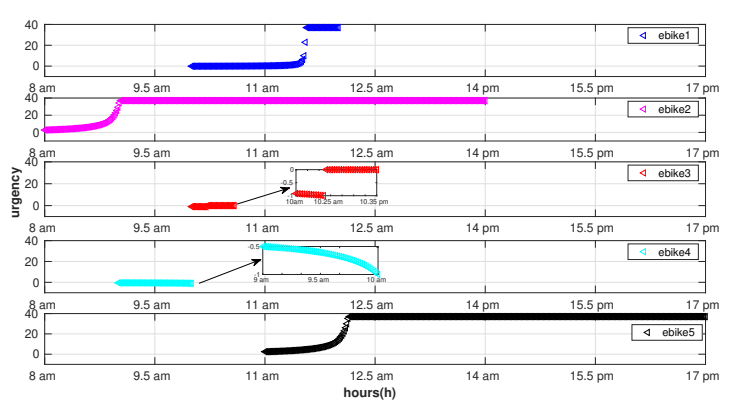

Figure 21: urgency of scenario 1. below zero, ebike's urgencies are extreme, the required charging time is less than the ebike parking time. Between $[0,1]$, the urgency is high, the parking time is greater than zero or equal to twice the charging time. Between [1,3], urgency is medium. The urgency is used to calculate the ebike charging priority.

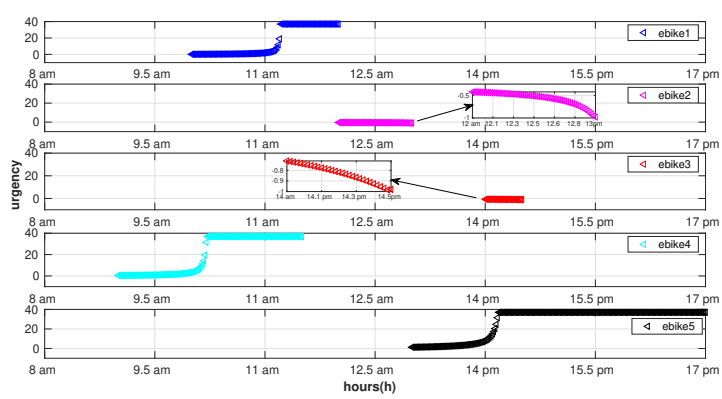

Figure 22: urgency of scenario 2. Below zero, ebike's urgencies are extreme, the required charging time is less than the ebike parking time. Between $[0,1]$, the urgency is high, the parking time is greater than zero or equal to twice the charging time. Between $[1,3]$, urgency is medium. The urgency is used to calculate the ebike charging priority

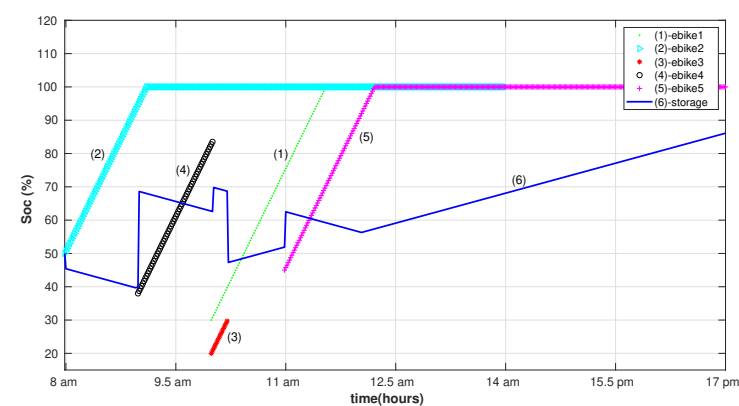

Figure 23: states of charge in scenario 1: it presents the state of charge variation of the both storage batterie and power-assisted bike at the charging station.

- the ebikes 1,2 and 5 are fully charged at the end of the parking time

- the ebike 3 and ebike 4 are charged at $29.7 \%$ and $83.52 \%$ respectively,

- the storage battery is charging at the same

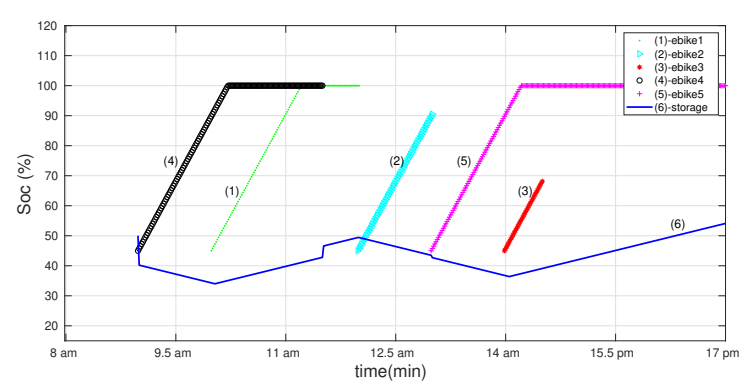

Figure 24: states of charge in scenario 2: This figure presents the variation in the states of charge of the both storage batterie and powerassisted bike at the charging station, over one day.

time as the ebike 1 ,

- during the permanence of the charging station (absence of ebike), the storage battery is gradually charging.

- the storage battery is discharging during the charging of ebike 2,3,4 and 5 .

\subsection{2. scenario 2}

The results of the scenario 2 show that:

- the storage battery is charging at the same time as the ebike1 and ebike3.

- the ebike 1, 4 and 5 are fully charged at the end of the parking.

- the storage battery is discharging during the charging of the ebike 2, ebike 4 and ebike 5 .

- ebike 2 and 3 initially at $45 \%$, are charged respectively at $90.52 \%$ and $68.13 \%$.

\section{1. energy gain and energy flexibility in the both scenario 1 and 2}

For each charging scenario, the charging with and without the ride's arduousness is examined and the charging energy supplied by the charging station in each case is calculated.

\subsection{1. scenario 1}

Figure 25 shows the energies used (with and without arduousness) to charge the ebikes' batteries in the scenario 1 .

The results show:

- a low value of the energy delivered by the charging station when the ride's arduousness is taken into account. This energy varies from 6Wh for ebike2, to 50Wh for ebike5 ; 


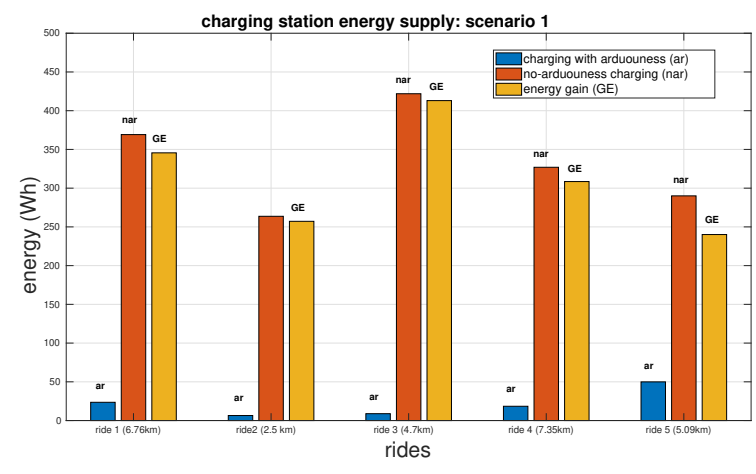

Figure 25: charging energy delivered to the ebike's batteries in the scenario 1: "charging with arduouness" represents the energy supplied by the charging station to the batteries of the power-assisted bikes, taking into account the rides' characteristics. In the "noarduousness charging", the characteristics of the rides are not taken into account. The arduousness gain also called energy gain $G_{E}$ is the energy saved at the charging station when the ride's arduousness is considered; $G_{E}$ is obtained by subtracting the charging energy without arduousness to the charging energy with arduousness.

- a significant value of the no-arduousness charging energy delivered by the charging station. It varies from $263.68 \mathrm{Wh}$ for ebike2 to $290.05 \mathrm{Wh}$ for ebike5 ;

- a significant gain of energy (Wh) when the rides' arduousness is considered. This gain varies from $240.13 \mathrm{Wh}$ for ebike 5 to 413.03Wh for ebike 3 .

The change observed in the energy gain, energies with and without arduousness is due to the fact that, ebikes do not have the same rides and states of charge.

The energy gains $G_{E}(\mathrm{Wh})$ and energy flexibility are presented in the table 13. The last column of the table 13 represents the fraction of the useful energy on the ride. It is the ratio between the charging energy with and without arduousness. The fourth column of the table 13 is the energy flexibility $f(\%)$. It represents the proportion of the energy saved when the arduousness is taken into account. For example, the value $2.10 \%$ obtained for the ebike 3 indicates that only $2.10 \%$ of energy provided by the charging station is used on the ride. Therefore, the remaining $93.62 \%$ is not needed for the ride. This remaining percentage represents the energy flexibility $f(\%)$.
Table 13: Gain and charging efficiency of scenario 1

\begin{tabular}{|c|c|c|c|c|c|}
\hline ebikes & Ecc $(\mathrm{Wh})$ & $\Delta E(\mathrm{Wh})$ & $G_{E}(\mathrm{Wh})$ & $f(\%)$ & $\eta(\%)$ \\
\hline ebike1 & 369.16 & 23.57 & 354.59 & 93.62 & 6.38 \\
\hline ebike2 & 263.68 & 6.48 & 257.20 & 97.54 & 2.46 \\
\hline ebike3 & 421.89 & 8.86 & 413.03 & 97.90 & 2.10 \\
\hline ebike4 & 326.97 & 18.44 & 308.53 & 94.36 & 5.64 \\
\hline ebike5 & 290.05 & 49.92 & 240.13 & 82.79 & 17.21 \\
\hline
\end{tabular}

\subsection{2. scenario 2}

The energy delivered by the charging station with and without arduousness in the scenario 2 is shown in Fig.26. The results show that the energy with and without arduousness, as well as the arduousness gain do not change. This is due to the fact that the ebike's states of charge and the rides are the same. The energy gain and the charging flex-

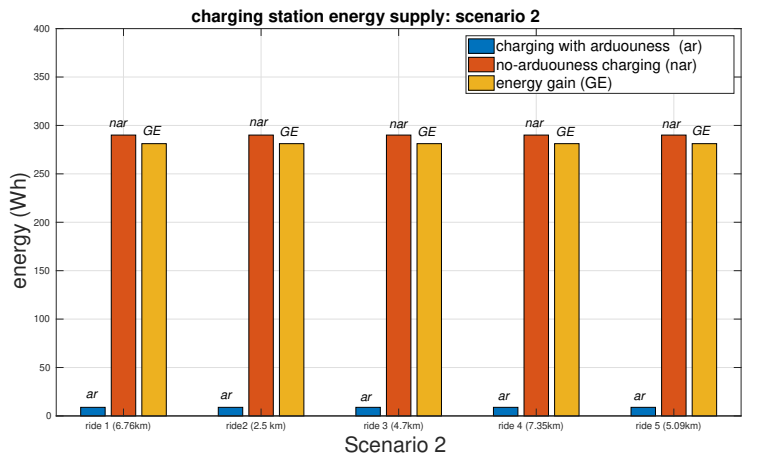

Figure 26: charging energy delivered to the ebike's batteries in the scenario 2: "charging with arduouness" represents the energy supplied by the charging station to the batteries of the power-assisted bikes, taking into account the rides' characteristics. In the "noarduousness charging", the characteristics of the rides are not taken into account. The arduousness gain also called energy gain $G_{E}$ is the energy saved at the charging station when the ride's arduousness is considered; $G_{E}$ is obtained by subtracting the charging energy without arduousness to the charging energy with arduousness.

ibility in the scenario 2 are presented in the Table 14. The results show that, when arduousness is not taken into account, only $3 \%$ of the energy provided for charging ebike is used on the ride.

The fraction of energy used on the rides in the

Table 14: gain and charging efficiency in the scenario 2

\begin{tabular}{|c|c|c|c|c|c|}
\hline ebike & Ecc $(\mathrm{Wh})$ & $\Delta E(\mathrm{Wh})$ & $G_{E}(\mathrm{Wh})$ & $f(\%)$ & $\eta(\%)$ \\
\hline ebikes 1,2,3,4,5 & 290.05 & 8.86 & 281.19 & 96.94 & 3.06 \\
\hline
\end{tabular}

both scenarios 1 and 2 is shown in the Figure 27. 


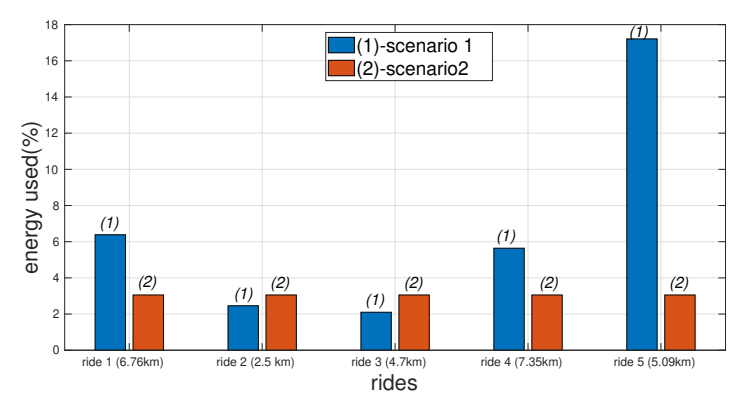

Figure 27: proportion of the energy used: this figure shows the energy used in the scenarios 1 and 2. It is the ratio between the energy required (taking into account the arduousness) for the ride and the no-arduousness energy provided by the charging station for each scenario.

\section{Discussions}

\section{1. scenario 1}

The changes of the switches from state " 1 " to state " 0 " of the ebikes 1,2 and 5 are justified by the full charge of ebikes (ebike state of charge is 100\%). In fact, when the ebikes are connected to the charging station, they have $30 \%, 50 \%$ and $45 \%$ as state of charge respectively. At the end of the charge, when the state of charge reaches $100 \%$, the switch automatically shifts to state " 0 ". This automatic shift improves the charging time of the other ebikes connected to the charging station. Indeed, the ebike are connected to a charging station with multiple charging spots ( single charger multiple cables (SMC) [1]) and the charging current is shared between the connected and priority ebikes. This kind of connection reduces the current intensity at the charging spots when the ebikes are connected simultaneously.

For ebike 3, the change in switch state is due to its low level of arduousness (ride 3). As ebike3 arduouness is low, it has a lower priority than ebike1 and ebike 2 when they are connected simultaneously to the charging station.

The high priority observed for ebike1, ebike 4 and ebike 5 is due to :

- their high arduousness indexes ( 0.60, 0.45 and 0.99 respectively);

- the short parking time for ebike1 and ebike4 ;

- their low initial state of charge $(30 \%, 38 \%$ and $45 \%$ respectively);
- the unavailability of photovoltaic power between 8:00 am and 10:30 am and after 3:00 $\mathrm{pm}$.

The low priority of ebike 2 and ebike 3 is due to:

- the high parking time (six hours) for the ebike2;

- their low arduousness indexes (0.21 and 0.20 respectively).

The extreme urgency observed for ebike 3 and 4 in the scenario 1 is due to the short parking time and the low initial state of charge of their batteries. Indeed, ebike 3 and ebike 4 have the states of charge of $20 \%$ and $38 \%$ respectively, then a parking time of 0.58 hour and 1 hour respectively.

The low urgency observed at the end of charge on the ebike 2 and ebike 5 is justified by the six-hour parking time ( 6 hours). The medium urgency observed at the beginning of the charge is justified by their initial states of charge which are $45 \%$ and $50 \%$ respectively.

\section{2. scenario 2}

In the scenario 2, the change of the switches from state " 1 " to state " 0 " of the ebikes 1,4 and 5 is justified by the full charge of their batteries.

The urgency observed for ebikes in the scenario 2 is justified by their parking times;

The extreme urgency of the ebike 2 , ebike 4 and ebike 3 is justified by their short parking time ( $1 \mathrm{~h}$ and $0.5 h$ respectively). For ebike 1,4 and 5 , the low urgency observed is justified by the parking time greater than and equal to two hours.

The low priority values of ebikes in the scenario 2 are justified by their low arduousness index (0.20).

\section{Conclusion}

In this work, the arduousness index is used to control the charging priority of the ebikes using continuous fuzzy logic. Automatic control of the switches on a SMC charging station with discrete fuzzy logic is performed. Several decision variables are used. The availability of photovoltaic power on the control horizon is determined with the artificial neural network. The benefits of the rides' arduousness for the charging stations are also presented. A comparative study of charging ebike with and without the ride's arduousness is 
performed, taking into account the energy delivered to the ebike batteries at the charging station. The developed control strategy is validated in the context of Polytech Annecy, at the Savoie Mont Blanc University in France.

The results show that:

- the arduousness index, associated with fuzzy logic, allows to manage the charging priority and the current dispatching to ebikes on a charging station;

- charging ebike based on the ride's arduousness saves energy unlike no-arduousness charge.

- In the presence of the ebikes connected to the charging station, the storage battery delivers energy to charge the ebike when the photovoltaic power output is lower than the charging demand on the one hand, and stores the surplus energy on the other hand.

\section{8. perspectives}

This study is applied to a charging station with single charger multiple cables, which limits the charging current in case of simultaneous connection of the ebikes. We are planning in the next works to:

- apply the developed control in a charging station with multiple chargers multiple cables, which will allow each charger to be assigned an independent charging current;

- add wind turbine and the grid to the photovoltaic solar panels to optimize the management of available energy;

- experimentally validate the developed control on a charging station set up in the laboratory building.

- use ebike's batteries as a backup source

- take into account regenerative braking when calculating rider assistance.

\section{Acknowledgements}

This work was supported by the CEA-MITIC and Eurasmus+ MIC funding programs.

\section{References}

[1] Y. Wu, A. Ravey, D. Chrenko, A. Miraoui, Demand side energy management of EV charging stations by approximate dynamic programming, Energy Conversion and Management 196 (2019) 878-890. doi:10.1016/j.enconman.2019.06.058.

[2] K. Liu, X. Hu, Z. Yang, Y. Xie, S. Feng, Lithium-ion battery charging management considering economic costs of electrical energy loss and battery degradation, Energy Conversion and Management 195 (2019) 167-179. doi:10.1016/j.enconman.2019.04.065.

[3] S. Micari, A. Polimeni, G. Napoli, L. Andaloro, V. Antonucci, Electric vehicle charging infrastructure planning in a road network, Renewable and Sustainable Energy Reviews 80 (2017) 98-108. doi:10.1016/j.rser.2017.05.022.

[4] M. A. Tamor, M. Milačić, Electric vehicles in multi-vehicle households, Transportation Research Part C: Emerging Technologies 56 (2015) 52-60. doi:10.1016/j.trc.2015.02.023.

[5] S. Habib, M. M. Khan, F. Abbas, H. Tang, Assessment of electric vehicles concerning impacts, charging infrastructure with unidirectional and bidirectional chargers, and power flow comparisons, International Journal of Energy Research 42 (11) (2018) 3416-3441. doi:10.1002/er.4033.

[6] K. M. Tan, V. K. Ramachandaramurthy, J. Y. Yong, Bidirectional battery charger for electric vehicle, in: 2014 IEEE Innovative Smart Grid Technologies - Asia (ISGT ASIA), 2014, pp. 406-411, iSSN: 2378-8542. doi:10.1109/ISGT-Asia.2014.6873826.

[7] X. Zhu, H. Han, S. Gao, Q. Shi, H. Cui, G. Zu, A Multi-Stage Optimization Approach for Active Distribution Network Scheduling Considering Coordinated Electrical Vehicle Charging Strategy, IEEE Access 6 (2018) 50117-50130. doi:10.1109/ACCESS.2018.2868606.

[8] L. Luo, W. Gu, S. Zhou, H. Huang, S. Gao, J. Han, Z. Wu, X. Dou, Optimal planning of electric vehicle charging stations comprising multi-types of charging facilities, Applied Energy 226 (2018) 1087-1099. doi:10.1016/j.apenergy.2018.06.014.

[9] M. D. Galus, M. G. Vayá, T. Krause, G. Andersson, The role of electric vehicles in smart grids, WIREs Energy and Environment 2 (4) (2013) 384-400. doi:10.1002/wene.56.

[10] T. U. Solanke, V. K. Ramachandaramurthy, J. Y. Yong, J. Pasupuleti, P. Kasinathan, A. Rajagopalan, A review of strategic charging-discharging control of grid-connected electric vehicles, Journal of Energy Storage 28 (2020) 101193. doi:10.1016/j.est.2020.101193.

[11] M. Ndiaye, P. Ndiaye, F. Guerin, D. Lefebvre, Optimal load sharing strategy in system of multiple source based on model control predictive, 29th Annual European Simulation and Modelling Conference 2015, ESM 2015 (2015) 237-244.

[12] M. Mohammadi Landi, M. Mohammadi, M. Rastegar, Simultaneous determination of optimal capacity and charging profile of plug-in electric vehicle parking lots in distribution systems, Energy 158 (2018) 504-511. doi:10.1016/j.energy.2018.06.065.

[13] M. F. Bandpey, K. G. Firouzjah, Two-stage charging strategy of plug-in electric vehicles based on fuzzy control, Computers \& Operations Research 96 (2018) 236-243. doi:10.1016/j.cor.2017.07.014.

[14] S. Nag, K. Y. Lee, Optimized Fuzzy Logic Controller for Responsive Charging of Electric Vehi- 
cles, IFAC-PapersOnLine 52 (4) (2019) 147-152. doi:10.1016/j.ifacol.2019.08.170.

[15] S. Çeven, A. Albayrak, R. Bayır, Real-time range estimation in electric vehicles using fuzzy logic classifier, Computers \& Electrical Engineering 83 (2020) 106577. doi:10.1016/j.compeleceng.2020.106577.

[16] M. F. El-naggar, A. A. A. Elgammal, Multi-Objective Optimal Predictive Energy Management Control of GridConnected Residential Wind-PV-FC-Battery Powered Charging Station for Plug-in Electric Vehicle 10.

[17] W. Li, T. Zhang, R. Wang, Energy Management Model of Charging Station Micro-Grid Considering Random Arrival of Electric Vehicles, in: 2018 IEEE International Conference on Energy Internet (ICEI), 2018, pp. 29-34. doi:10.1109/ICEI.2018.00013.

[18] E. Xydas, C. Marmaras, L. M. Cipcigan, A multiagent based scheduling algorithm for adaptive electric vehicles charging, Applied Energy 177 (2016) 354-365. doi:10.1016/j.apenergy.2016.05.034

[19] L. K. Panwar, K. S. Reddy, R. Kumar, B. K. Panigrahi, S. Vyas, Strategic Energy Management (SEM) in a micro grid with modern grid interactive electric vehicle, Energy Conversion and Management 106 (2015) 41-52. doi:10.1016/j.enconman.2015.09.019.

[20] M. R. Mozafar, M. H. Moradi, M. H. Amini, A simultaneous approach for optimal allocation of renewable energy sources and electric vehicle charging stations in smart grids based on improved GA-PSO algorithm, Sustainable Cities and Society 32 (2017) 627-637. doi:10.1016/j.scs.2017.05.007.

[21] K. Zhang, Y. Mao, S. Leng, Y. He, S. Maharjan, S. Gjessing, Y. Zhang, D. H. K. Tsang, Optimal Charging Schemes for Electric Vehicles in Smart Grid: A Contract Theoretic Approach, IEEE Transactions on Intelligent Transportation Systems 19 (9) (2018) 3046-3058. doi:10.1109/TITS.2018.2841965.

[22] Optimal Minimization of Plug-In Electric Vehicle Charging Cost With Vehicle-to-Home and Vehicle-to-Grid Concepts - IEEE Journals \& Magazine.

[23] S. Ji, C. R. Cherry, L. D. Han, D. A. Jordan, Electric bike sharing: simulation of user demand and system availability, Journal of Cleaner Production 85 (2014) 250-257. doi:10.1016/j.jclepro.2013.09.024

[24] I. Frade, A. Ribeiro, Bike-sharing stations: A maximal covering location approach, Transportation Research Part A: Policy and Practice 82 (2015) 216-227. doi:10.1016/j.tra.2015.09.014

[25] Y.-W. Chen, C.-Y. Cheng, S.-F. Li, C.-H. Yu, Location optimization for multiple types of charging stations for electric scooters, Applied Soft Computing 67 (2018) 519528. doi:10.1016/j.asoc.2018.02.038.

[26] M. Joševski, D. Abel, Flatness-based Trajectory Planning for the Battery State of Charge in Hybrid Electric Vehicles, IFAC-PapersOnLine 49 (11) (2016) 134-140. doi:10.1016/j.ifacol.2016.08.021. URL https://linkinghub.elsevier.com/retrieve/p

[27] O. Cisse, M. Ndiaye, W. Nkounga, A. Sioutas, Water and Energy Management based on Fuzzy Logic and Linear Programming for a Photovoltaic/Wind/Battery Pumping System in Rural Environment, 2018.

[28] L. Suganthi, S. Iniyan, A. A. Samuel, Applications of fuzzy logic in renewable energy systems - A review, Renewable and Sustainable Energy Reviews 48 (2015) 585607. doi:10.1016/j.rser.2015.04.037.

[29] H. Zhang, A. Davigny, F. Colas, Y. Poste, B. Robyns,
Fuzzy logic based energy management strategy for commercial buildings integrating photovoltaic and storage systems, Energy and Buildings 54 (2012) 196-206. doi:10.1016/j.enbuild.2012.07.022.

[30] M. Vakili, S.-R. Sabbagh-Yazdi, K. Kalhor, S. Khosrojerdi, Using Artificial Neural Networks for Prediction of Global Solar Radiation in Tehran Considering Particulate Matter Air Pollution, Energy Procedia 74 (2015) 12051212. doi:10.1016/j.egypro.2015.07.764.

[31] F. Rodríguez, A. Fleetwood, A. Galarza, L. Fontán, Predicting solar energy generation through artificial neural networks using weather forecasts for microgrid control, Renewable Energy 126 (2018) 855-864. doi:10.1016/j.renene.2018.03.070.

[32] H. Wang, R. Cai, B. Zhou, S. Aziz, B. Qin, N. Voropai, L. Gan, E. Barakhtenko, Solar irradiance forecasting based on direct explainable neural network, Energy Conversion and Management 226 (2020) 113487. doi:10.1016/j.enconman.2020.113487.

[33] W. M. NKOUNGA, M. F. NDIAYE, M. L. NDIAYE, O. CISSE, M. BOP, A. SIOUTAS, Short-term forecasting for solar irradiation based on the multi-layer neural network with the Levenberg-Marquardt algorithm and meteorological data: application to the Gandon site in Senegal, in: 2018 7th International Conference on Renewable Energy Research and Applications (ICRERA), 2018, pp. 869-874, iSSN: 2572-6013. doi:10.1109/ICRERA.2018.8566850.

[34] W. M. Nkounga, M. F. Ndiaye, M. L. Ndiaye, F. Grandvaux, L. Tabourot, M. Conde, Sizing Optimization of a Charging Station Based on the Multi-scale Current Profile and Particle Swarm Optimization: Application to Power-assisted Bikes, in: 2021 Sixteenth International Conference on Ecological Vehicles and Renewable Energies (EVER), IEEE, Monte-Carlo, Monaco, 2021, pp. 1-12. doi:10.1109/EVER52347.2021.9456626.

URL ht tps: //ieeexplore. ieee.org/document/9456626/

[35] Calcul de distance avec latitudes et longitudes.

[36] L. Liu, T. Suzuki, Quantifying e-bike applicability by comparing travel time and physical energy expenditure: A case study of Japanese cities, Journal of Transport \& Health 13 (2019) 150-163. doi: $10.1016 / j . j$ th. 2019.04 .001 .

[37] A. Lucía, J. Hoyos, A. Santalla, M. Pérez, J. L. Chicharro, Curvilinear VO2:Power Output Relationship in a Ramp Test in Professional Cyclists: Possible Association with Blood Hemoglobin Concentration., The Japanese Journal of Physiology 52 (1) (2002) 95-103. doi:10.2170/jjphysiol.52.95.

[38] W. M. Nkounga, M. F. Ndiaye, O. Cisse, M. Bop, M. L. Ndiaye, F. Grandvaux, L. Tabourot, Short-term Multi Horizons Forecasting of Solar Irradiation Based on Artificial Neural Network with Meteorological Data: Application in the North-west of Senegal, in: 2021 Sixteenth International Conference on Ecological Vehicles and Re/pi i/S24058963116ad131428nergies (EVER), IEEE, Monte-Carlo, Monaco, 2021, pp. 1-8. doi:10.1109/EVER52347.2021.9456600. URL ht tps: //ieeexplore. ieee.org/document/9456600/

[39] Bike map | Cycle route planner $\mid$ cycle.travel.

[40] CAMS radiation service - www.soda-pro.com. 